\title{
Parameter Space of Atomic Layer Deposition of Ultrathin Oxides on Graphene
}

\author{
Adrianus I. Aria, Kenichi Nakanishi, Long Xiao, Philipp Braeuninger-Weimer, Abhay A. Sagade, \\ Jack A. Alexander-Webber, and Stephan Hofmann* \\ Division of Electrical Engineering, Department of Engineering, University of Cambridge, Cambridge CB3 OFA, United Kingdom
}

Supporting Information

ABSTRACT: Atomic layer deposition (ALD) of ultrathin aluminum oxide $\left(\mathrm{AlO}_{x}\right)$ films was systematically studied on supported chemical vapor deposition (CVD) graphene. We show that by extending the precursor residence time, using either a multiple-pulse sequence or a soaking period, ultrathin continuous $\mathrm{AlO}_{x}$ films can be achieved directly on graphene using standard $\mathrm{H}_{2} \mathrm{O}$ and trimethylaluminum (TMA) precursors even at a high deposition temperature of $200{ }^{\circ} \mathrm{C}$, without the use of surfactants or other additional graphene surface modifications. To obtain conformal nucleation, a precursor residence time of $>2 s$ is needed, which is not

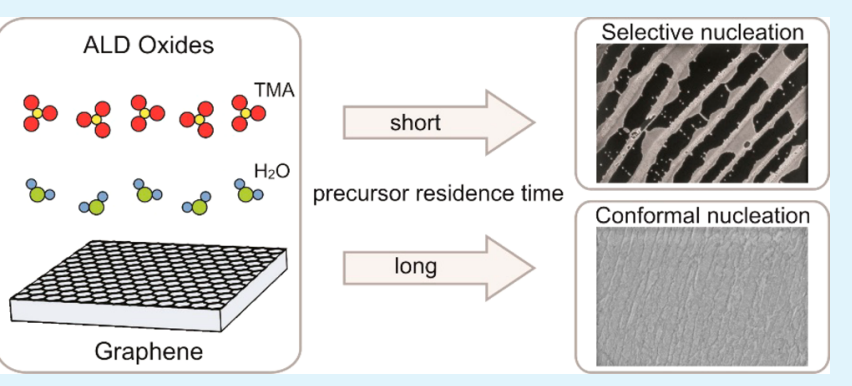
prohibitively long but sufficient to account for the slow adsorption kinetics of the graphene surface. In contrast, a shorter residence time results in heterogeneous nucleation that is preferential to defect/selective sites on the graphene. These findings demonstrate that careful control of the ALD parameter space is imperative in governing the nucleation behavior of $\mathrm{AlO} \mathrm{O}_{x}$ on CVD graphene. We consider our results to have model system character for rational two-dimensional (2D)/non-2D material process integration, relevant also to the interfacing and device integration of the many other emerging $2 \mathrm{D}$ materials.

KEYWORDS: graphene, atomic layer deposition, aluminum oxide, ultrathin films, conformal deposition

\section{INTRODUCTION}

Two-dimensional (2D) materials, such as graphene, offer new and improved functionalities for a wide range of applications ranging from electronics and photonics to energy conversion and storage devices. ${ }^{1}$ The effective properties of $2 \mathrm{D}$ materials are, however, extremely dependent on their environment, and hence their route to applications critically requires precise control of interfacing and integration in particular with established non-2D materials including metals, metal oxides, and polymers. Characteristics for 2D materials are their strong, predominantly covalent, intralayer bonding, contrasted by their weak out-of-plane interactions dominated by van der Waals forces. Because of these weak out-of-plane interactions, it remains extremely challenging to grow ultrathin continuous layers of such standard materials on top of $2 \mathrm{D}$ materials, be it as dielectric, barrier, dopant, contact, light emitter/absorber, carrier recombinator/separator, catalyst, or structural support. $^{2-10}$ The properties of a $2 \mathrm{D}$ material interfaced with a conventional thin film are thereby not merely dictated by the quality of the components. A significant challenge is to provide an optimum interface between the $2 \mathrm{D}$ and $3 \mathrm{D}$ structure, which requires a detailed understanding of the various growth modes and of 2D/non-2D material interfacing. Almost all 2D-based electrical devices, for instance, require not only metallic contacts but also interfacing to a common dielectric. While progress has been made in the scalable process integration of chemical vapor deposition (CVD) of $2 \mathrm{D}$ materials with atomic layer deposition (ALD) of ultrathin metal oxides, ${ }^{7,11,12}$ a fundamental understanding of such interfacing remains in its infancy, hindering the rational process and device design for $2 \mathrm{D} /$ non-2D integration.

Here, we focus on the nucleation behavior of ALD aluminum oxide $\left(\mathrm{AlO}_{x}\right)$ on supported CVD graphene, systematically exploring the ALD growth modes and the governing conditions for achieving either selective or conformal $\mathrm{AlO}_{x}$ deposition on graphene that is either supported by its original growth catalyst or transferred with various levels of defects, wrinkles, and contamination. To date, the most common approaches to enhancing wetting for graphene and, hence, achieving a high $\mathrm{AlO}_{x}$ nucleation density and more conformal coverage employ either lower deposition temperatures $\left(T_{\text {dep }}\right)$ or a surface modification of the graphene using seed layers, functional groups, and a more reactive oxidant to uniformly activate the graphene surface. ${ }^{2,12-20}$ However, such approaches can not only degrade the $\mathrm{AlO}_{x}$ film properties and/or the graphene but also introduce additional elements/states at the interface that can be deleterious to the device functionality. Hence, here we do not employ any additional graphene surface modification but rather focus on the details of the ALD parameter space. Because ALD depends heavily on surface saturation to achieve

Received: August 2, 2016

Accepted: October 10, 2016

Published: October 10, 2016 


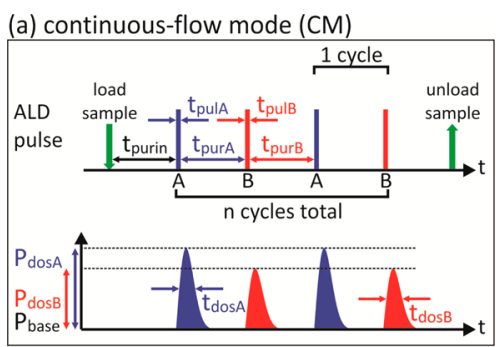

(c) multipulse mode (MM)

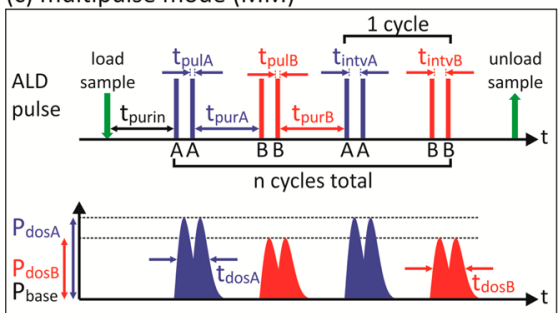

(b) pretreatment mode (PM)
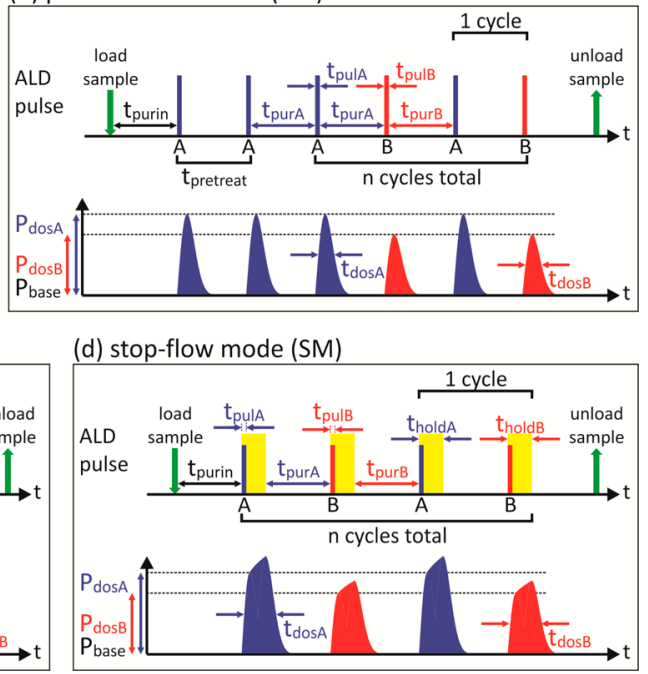

Figure 1. Schematic of the ALD process in (a) CM, (b) PM, (c) MM, and (d) SM. A denotes the oxidant, here $\mathrm{H}_{2} \mathrm{O}$ vapor or $\mathrm{O}_{3}$, and B denotes the metal precursor, here TMA. The oxidant/precursor dose is calculated from the product of the delivery pressure $\left(P_{\text {dos }}\right)$ and the residence time $\left(t_{\text {dos }}\right)$, which in CM and PM are both governed by a single-parameter ALD pulse time $\left(t_{\text {pul }}\right)$. All samples are loaded while the chamber is at the preset deposition temperature $\left(T_{\text {dep }}\right)$, and the process chamber is purged with $\mathrm{N}_{2}$ for more than $10 \mathrm{~min}\left(t_{\text {purin }}\right)$ before the ALD process is started. The purge time between the oxidant/precursor pulses $\left(t_{\text {pur }}\right)$ is varied between 10 and $60 \mathrm{~s}$ depending on $T_{\text {dep. }}$. In PM, the samples are exposed to a series of oxidant pulses prior to the ALD process, where the pretreatment time $\left(t_{\text {pretreat }}\right)$ is determined by the total number of pulses. In MM, each oxidant/ precursor is delivered twice in quick succession with a very short time interval $\left(t_{\text {intv }}\right)$. Thus, $t_{\text {dos }}$ in MM can be twice as long as that in CM for the same $P_{\text {dos }}$. In SM, the flow in the process chamber is stopped for several seconds $\left(t_{\text {hold }}\right)$ to allow the samples to be soaked in the oxidant/precursor. Therefore, $t_{\mathrm{dos}}$ in SM can be adjusted independently from $P_{\mathrm{dos}}$.

the self-limiting sequential reactions, the nucleation behavior is mainly governed by three parameters: the available amount of oxidant/precursor for reaction, their mass transport to the surface, and the surface reaction kinetics. ${ }^{21,22}$ We address the choice of these parameters in detail to control $\mathrm{AlO}_{x}$ deposition on CVD graphene. We show that by extending the precursor residence time, by either optimizing the pulse sequences or introducing a soaking period, we are able to overcome the otherwise heterogeneous nucleation that is limited to defect/ selective sites and highly dependent on support such as layer numbers and the underlying metal. As demonstrated herein, sub-2-nm thin continuous $\mathrm{AlO}_{x}$ films can be achieved directly on graphene using standard water $\left(\mathrm{H}_{2} \mathrm{O}\right)$ and trimethylaluminum (TMA) precursors even at a high $T_{\text {dep }}$ of $200{ }^{\circ} \mathrm{C}$. Such a capability to directly integrate a thin continuous $\mathrm{AlO}_{x}$ film, an archetypical high- $\kappa$ dielectric, with graphene would allow the further development of a wide range of applications that utilize graphene as the channel material. ${ }^{23}$

\section{MATERIALS AND METHODS}

$\mathrm{AlO}_{x}$ films were deposited directly by ALD on four different sets of samples: graphene grown on copper metal catalysts $(\mathrm{G} / \mathrm{Cu})$, graphene grown on germanium substrates $(\mathrm{G} / \mathrm{Ge})$, graphene transferred on $\mathrm{SiO}_{2}$ substrates $\left(\mathrm{G} / \mathrm{SiO}_{2}\right)$, and highly oriented pyrolytic graphite (HOPG; Agar Scientific, $3.5 \pm 1.5$ mosaic spread). These samples were selected to represent different types of supported graphene because it has been previously shown that the $\mathrm{AlO}_{x}$ nucleation behavior is strongly affected by the underlying support. ${ }^{17}$ The $\mathrm{G} / \mathrm{Cu}$ samples were grown by $\mathrm{CVD}$ using a $\mathrm{H}_{2}$-diluted $\mathrm{CH}_{4}(0.1 \%$ in argon) precursor at a partial pressure of $\sim 10^{-3} \mathrm{mbar}$ and a temperature of 950-1000 ${ }^{\circ} \mathrm{C}$ on polycrystalline copper foils (Alfa Aesar, $25 \mu \mathrm{m}$ thickness, $99.8 \%$ purity), which have been electrochemically polished prior to CVD using diluted $\mathrm{H}_{3} \mathrm{PO}_{4}$ (85\% aqueous solution, further diluted in $\mathrm{H}_{2} \mathrm{O}$ with a 7:3 ratio) under a constant voltage of $2.7 \mathrm{~V}$ for 7-15 min. ${ }^{24}$ The G/Ge samples were grown by CVD on a monocrystalline germanium wafer (110) using a $\mathrm{H}_{2}$-diluted $\mathrm{CH}_{4}$
$\left(\mathrm{CH}_{4} / \mathrm{H}_{2}\right.$ ratio of 1:52) precursor at a partial pressure of $\sim 1 \mathrm{mbar}$ and a temperature of $920{ }^{\circ} \mathrm{C}$. The $\mathrm{G} / \mathrm{SiO}_{2}$ samples were fabricated by transferring the graphene layer from $\mathrm{G} / \mathrm{Cu}$ to $\mathrm{SiO}_{2}$ substrates (silicon wafer with a $300 \mathrm{~nm}$ native oxide) using a polymer support (Microchem 950PMMA A4) and wet chemical etching (0.5 M $\mathrm{FeCl}_{3}$ and $37 \% \mathrm{HCl}$ ), followed by a cleaning process in acetone and $\mathrm{H}_{2}$ annealing at a partial pressure of $\sim 1$ mbar and a temperature of 200 ${ }^{\circ} \mathrm{C}$, as described in detail elsewhere. ${ }^{25,26}$ All CVD and transferred graphene samples used herein were predominantly monolayer graphene (MLG) with complete coverage over the substrates with a size of $>1 \times 1 \mathrm{~cm}^{2}$. To ensure that the findings in this study were consistent and not skewed by changes in the sample wettability due to adventitious carbon contamination from ambient air, ${ }^{24}$ ALD was performed within 7 days after CVD or a transfer process for $\mathrm{G} / \mathrm{Cu}, \mathrm{G} /$ $\mathrm{Ge}$, and $\mathrm{G} / \mathrm{SiO}_{2}$ and within 15 min subsequent to mechanical cleavage for HOPG.

$\mathrm{AlO}_{x}$ films were deposited on all samples by ALD (Cambridge Nanotech Savannah S100 G1) using trimethylaluminum (TMA; purity $>98 \%$, Strem Chemicals 93-1360) as the precursor, and unless stated otherwise, the vapor of deionized water $\left(\mathrm{H}_{2} \mathrm{O}\right)$ as the oxidant was delivered alternatingly into the reaction chamber by $20 \mathrm{sccm}$ of a $\mathrm{N}_{2}$ flow. During ALD, TMA and $\mathrm{H}_{2} \mathrm{O}$ were volatized at a temperature of $40{ }^{\circ} \mathrm{C}$, and when ozone $\left(\mathrm{O}_{3}\right)$ was used as the oxidant in place of $\mathrm{H}_{2} \mathrm{O}$, it was supplied by an ozone generator (DELOzone LG-7, 90\% power output) at room temperature. The deposition temperature $\left(T_{\text {dep }}\right)$ was varied between 80 and $200{ }^{\circ} \mathrm{C}$. All samples were loaded and unloaded while the chamber was at $T_{\text {dep }}$ without bringing the temperature down to room temperature. Prior to ALD, the chamber was pumped until it reached a base pressure $\left(P_{\text {base }}\right)$ of $\sim 4.5 \times 10^{-1}$ Torr, while being purged with $20 \mathrm{sccm}$ of a $\mathrm{N}_{2}$ flow for at least $10 \mathrm{~min}\left(t_{\text {purin }}\right)$. To prevent premature or CVD-like reactions, the chamber was purged after each delivery of an oxidant/precursor with $20 \mathrm{sccm}$ of a $\mathrm{N}_{2}$ flow and a purging time $\left(t_{\text {pur }}\right)$ that varied depending on $T_{\text {dep }}: 60 \mathrm{~s}$ purge for $80{ }^{\circ} \mathrm{C}$, $45 \mathrm{~s}$ purge for $120^{\circ} \mathrm{C}, 30 \mathrm{~s}$ purge for $150^{\circ} \mathrm{C}, 20 \mathrm{~s}$ purge for 180 ${ }^{\circ} \mathrm{C}$, and $12 \mathrm{~s}$ purge for $200{ }^{\circ} \mathrm{C}$. Unless stated otherwise, the total number of ALD cycles was always limited to only 12 cycles to highlight the nucleation process because a higher number of cycles usually results in a more uniform deposition. For consistency, the oxidant/precursor dose is always approximated by the product of the 

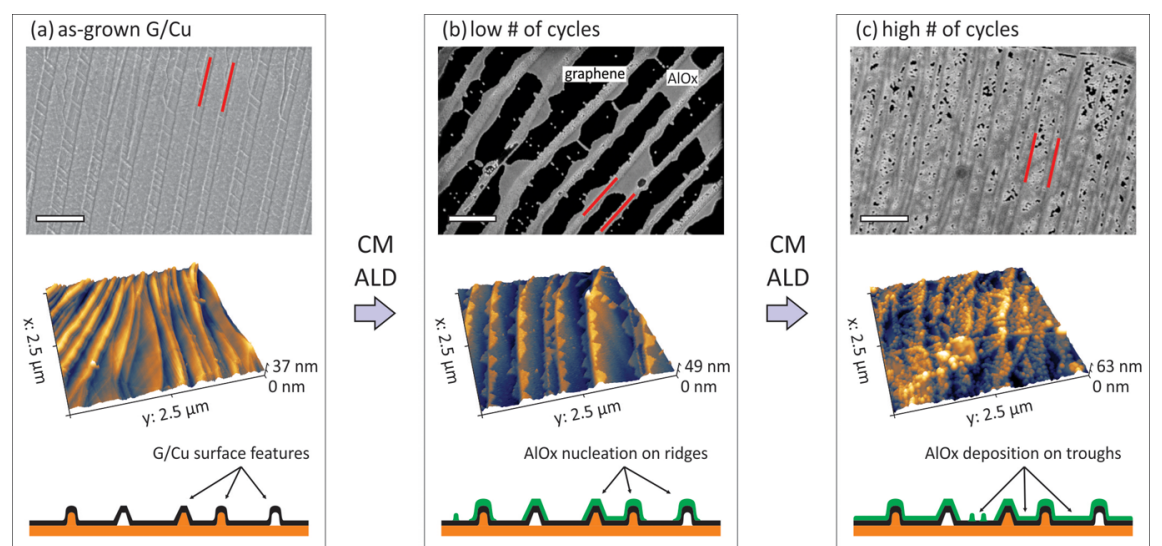

Figure 2. SSEM and AFM images of typical CVD G/Cu before (a) and after (b and c) ALD of $\mathrm{AlO}_{x}$ in $\mathrm{CM}$ at $T_{\text {dep }}$ of $200{ }^{\circ} \mathrm{C}$. (a) Surface topography of the as-grown CVD G/Cu is dominated by graphene wrinkles and $\mathrm{Cu}$ surface reconstructions with average heights of $10-25 \mathrm{~nm}$ and interspacings of $200-600 \mathrm{~nm}$. (b) $\mathrm{AlO}_{x}$ deposition on G/Cu with only $12 \mathrm{ALD}$ cycles, demonstrating the nature of the nucleation process that is highly preferential to the ridges. (c) $\mathrm{AlO}_{x}$ deposition on $\mathrm{G} / \mathrm{Cu}$ with $100 \mathrm{ALD}$ cycles, demonstrating the eventual complete surface coverage due to deposition on the troughs as the number of ALD cycles increases. In parts $b$ and $c$, the dark regions indicate the uncovered graphene surface, while the bright regions indicate the presence of $\mathrm{AlO}_{x}$ clusters/films on the graphene surface. All scale bars represent $500 \mathrm{~nm}$, and the red parallel lines indicate the ridges of $\mathrm{G} / \mathrm{Cu}$ surface features.

delivery pressure $\left(P_{\text {dos }}\right)$ and residence time $\left(t_{\text {dos }}\right)$, which are determined by the maximum and full-width at half-maximum (fwhm) values of the chamber pressure profile when the dose is delivered. We avoid the use of pulse time $\left(t_{\text {pul }}\right)$ as a measurement metric because the same $t_{\text {pul }}$ may result in different $P_{\text {dos }}$ and $t_{\text {dos }}$ if the carrier gas flow rate, pumping speed, and amount of oxidant/precursor available for volatilization are varied.

To elucidate the effect of the ALD parameters on the $\mathrm{AlO}_{x}$ nucleation behavior on graphene, ALD was performed under four distinct processes: continuous-flow mode $(\mathrm{CM})$, pretreatment mode (PM), multipulse mode (MM), and stopped-flow mode (SM). Schematic representations of these processes are shown in Figure 1. CM (Figure 1a) is an ALD mode commonly used in previous literature, ${ }^{12-14,18}$ where $\mathrm{H}_{2} \mathrm{O}$ and TMA are dosed alternatingly into the reaction chamber and separated by the purging periods. The effect of the oxidant/precursor doses was investigated by varying the $\mathrm{H}_{2} \mathrm{O}$ / TMA doses between $\sim 0.14$ and $\sim 2.1$ Torr $\cdot \mathrm{s}$, obtained by pulsing $\mathrm{H}_{2} \mathrm{O}$ $\left(t_{\text {pulA }}\right)$ between 15 and $300 \mathrm{~ms}$ and TMA $\left(t_{\text {pulB }}\right)$ between 15 and 100 ms. In CM, the doses for both $\mathrm{H}_{2} \mathrm{O}$ and TMA are always set equally, while the dose for $\mathrm{O}_{3}$, when it is used as the oxidant, is always set at a constant value of $\sim 30$ Torr.s. PM (Figure 1b) was used here to introduce a surface modification to the sample without the addition of seed layers but rather by exposure to a series of $\mathrm{H}_{2} \mathrm{O}$ or $\mathrm{O}_{3}$ pulses for a certain period of pretreatment time $\left(t_{\text {pretreat }}\right)$ prior to $\mathrm{AlO}_{x}$ deposition. Here, $t_{\text {pretreat }}$ is varied between 10 and 300 min for $\mathrm{H}_{2} \mathrm{O}$ pretreatment and between 2 and $15 \mathrm{~min}$ for $\mathrm{O}_{3}$ pretreatment. The oxidant dose and purging time in the pretreatment period are the same as those in the subsequent deposition period, which is performed under the same conditions as those in CM. The extended oxidant/precursor residence time is introduced herein by the use of a sequence of multiple pulses in MM and soaking periods in SM. In MM (Figure 1c), each reactant/ precursor dose is delivered by a sequence of two consecutive pulses in quick succession. The time interval $\left(t_{\text {intv }}\right)$ between these pulses is adjusted in such a way that $t_{\text {dos }}$ becomes the sum of the fwhm of both pulses. In SM (Figure 1d), the oxidant/precursor soaking period is introduced by stopping the flow to create a static atmosphere in the process chamber for several seconds ( $t_{\text {hold }}$ ) right after the oxidant/ precursor is dosed. Therefore, the dose in SM is controlled by two independent parameters, $t_{\mathrm{pul}}$ and $t_{\text {hold }}$. Before the subsequent dose, the flow is continued and the chamber is purged. The effect of the oxidant/precursor residence time in $\mathrm{MM}$ and $\mathrm{SM}$ was investigated by varying the $\mathrm{H}_{2} \mathrm{O} / \mathrm{TMA} t_{\text {dos }}$ between $\sim 2.5$ and $\sim 3.5 \mathrm{~s}$ while keeping all of the other ALD conditions the same as those in CM. Further details of the ALD parameters are described in the Supporting Information (section SI1).
The $\mathrm{AlO}_{x}$ nucleation was characterized by scanning electron microscopy (SEM; Carl Zeiss SIGMA VP) at an acceleration voltage of $2 \mathrm{kV}$ and atomic force microscopy (AFM; Digital Instruments Dimension 3100) under tapping mode at a scanning frequency of 1 $\mathrm{Hz}$. The $\mathrm{AlO}_{x}$ surface coverage $(\theta)$ was calculated based on the contrast observed in SEM images, with bright regions indicating areas of the graphene surface that are covered by $\mathrm{AlO}_{x}$ films/clusters and dark regions indicating the absence of $\mathrm{AlO}_{x}$. Further details of the surface coverage calculation are described in the Supporting Information (section SI2).

\section{RESULTS}

Figure 2 shows the typical surface topography of CVD graphene on $\mathrm{G} / \mathrm{Cu}$ prior and subsequent to $\mathrm{ALD} \mathrm{AlO}_{x}$ using CM (Figure 1a). Because of the nature of the CVD method used for the growth, the surface topography of $\mathrm{G} / \mathrm{Cu}$ is dominated by uniaxial graphene wrinkles and $\mathrm{Cu}$ surface reconstructions with an average height of $10-25 \mathrm{~nm}$ and an interspacing of $200-600 \mathrm{~nm},{ }^{27-30}$ which is equivalent to an average feature aspect ratio of much less than unity and a rootmean-square (rms) surface roughness of $\sim 5 \mathrm{~nm}$ (Figure 2a). When ALD is performed in CM (Figure 1a) under typical conditions of $T_{\text {dep }}$ of $200{ }^{\circ} \mathrm{C}$ and a TMA $/ \mathrm{H}_{2} \mathrm{O}$ dose of $\sim 0.14$ Torr's, which is obtained by the commonly used $t_{\text {pulA }}$ and $t_{\text {pulB }}$ settings of $15-30 \mathrm{~ms},{ }^{17,31,32}$ the nucleation behavior on $\mathrm{G} / \mathrm{Cu}$ is highly influenced by the presence of $\mathrm{G} / \mathrm{Cu}$ surface features. For a low number of ALD cycles, in this case 12 cycles, $\mathrm{AlO}_{x}$ is observed to nucleate preferentially on the ridges of these features, while the troughs are still relatively, although not entirely, free from $\mathrm{AlO}_{x}$ (Figure $2 \mathrm{~b}$ ). ${ }^{32}$ Under these ALD conditions, $\mathrm{AlO}_{x}$ deposition in the troughs occurs subsequently when $\mathrm{G} / \mathrm{Cu}$ is subjected to further ALD cycles, and a high number of ALD cycles will eventually lead to complete coverage of the $\mathrm{G} / \mathrm{Cu}$ surface. This behavior was observed after 100 ALD cycles, at which point the $\mathrm{AlO}_{x}$ layer almost completely encapsulates the $\mathrm{G} / \mathrm{Cu}$ surface, including the troughs (Figure 2c). Note that the topography of the deposited $\mathrm{AlO}_{x}$ layer resembles islandlike clusters, rather than a smooth film, implying a Volmer-Weber-type nucleation mode. ${ }^{33}$

The highly selective $\mathrm{AlO}_{x}$ nucleation behavior on $\mathrm{G} / \mathrm{Cu}$ at $T_{\text {dep }}$ of $200{ }^{\circ} \mathrm{C}$ leads to the assumption that a lower $T_{\text {dep }}$ is a 

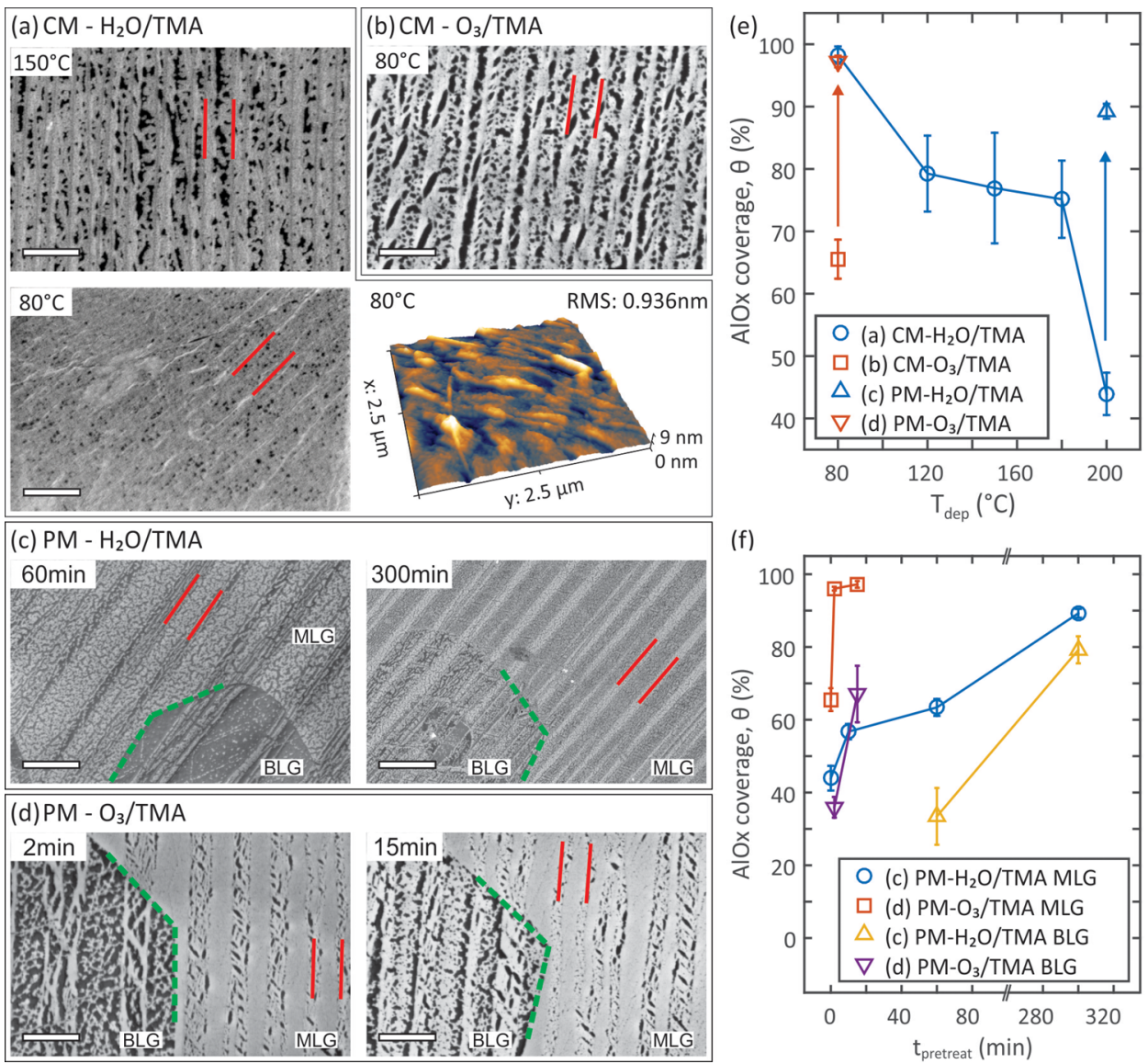

Figure 3. (a) $\mathrm{AlO}_{x}$ nucleation by ALD in CM using $\mathrm{H}_{2} \mathrm{O} / \mathrm{TMA}$ at $T_{\text {dep }}$ of 150 and $80{ }^{\circ} \mathrm{C}$. At a $T_{\text {dep }}$ of $80{ }^{\circ} \mathrm{C}$, the $\mathrm{AlO} \mathrm{O}_{x}$ coverage $(\theta)$ on the $\mathrm{G} / \mathrm{Cu}$ surface is almost perfectly complete with a considerably smooth surface topography, suggesting condensation of the oxidant/precursor during the ALD process. (b) $\mathrm{AlO}_{x}$ nucleation by ALD in CM using $\mathrm{O}_{3} / \mathrm{TMA}$ at a $T_{\text {dep }}$ of $80{ }^{\circ} \mathrm{C}$. $\mathrm{AlO}_{x}$ nucleation by ALD in PM using (c) $\mathrm{H}_{2} \mathrm{O} / \mathrm{TMA}$ with pretreatment times $\left(t_{\text {pretreat }}\right)$ of 60 and $300 \mathrm{~min}$ at a $T_{\text {dep }}$ of $200{ }^{\circ} \mathrm{C}$ and using $(\mathrm{d}) \mathrm{O}_{3} / \mathrm{TMA}$ with $t_{\text {pretreat }}$ of 2 and $15 \mathrm{~min}$ at a $T_{\text {dep }}$ of $80{ }^{\circ} \mathrm{C}$. The use of pretreatment significantly changes the selective nature of $\mathrm{AlO}_{x}$ nucleation into a more homogeneous nucleation. The green dotted lines in parts $\mathrm{c}$ and $\mathrm{d}$ indicate the boundaries between MLG and BLG, where the regions enclosed by the lines represent BLG. (e) Plot of $\theta$ on G/Cu by ALD in $\mathrm{CM}$ as a function of $T_{\text {dep }}$ based on parts a and $\mathrm{b}$. The red/blue arrows in part e indicate the improvement in $\theta$ when ALD is performed in PM, as observed in parts $\mathrm{c}$ and d, at the same $T_{\text {dep }}$. (f) Plot of $\theta$ on the G/Cu surface by ALD in PM as a function of $t_{\text {pretreat }}$ as observed in parts c and d, where a $t_{\text {pretreat }}$ of $0 \mathrm{~min}$ corresponds to CM. All scale bars in parts a-d represent $500 \mathrm{~nm}$, and the red parallel lines indicate the ridges of G/Cu surface features. The error bars in parts e and $\mathrm{f}$ indicate the standard deviation from the mean. The doses for $\mathrm{H}_{2} \mathrm{O}$ and TMA in both CM and PM are maintained at $\sim 0.14$ Torr $\cdot s$, while that for $\mathrm{O}_{3}$ is set at $\sim 28.65$ Torr $\cdot$. $\mathrm{All}^{\mathrm{AlO}_{x}}$ depositions are performed with 12 ALD cycles total.

necessary condition for achieving a more homogeneous nucleation with $\mathrm{H}_{2} \mathrm{O} /$ TMA. $^{16,17,33-35}$ Indeed, a significant change in the $\mathrm{AlO}_{x}$ nucleation behavior could be achieved by simply altering $T_{\text {dep }}$ while keeping the other deposition parameters constant. As shown in Figure 3a, a significantly higher nucleation density in the troughs is observed when $T_{\text {dep }}$ is decreased to $150{ }^{\circ} \mathrm{C}$ while maintaining a constant $\mathrm{TMA} / \mathrm{H}_{2} \mathrm{O}$ dose of $\sim 0.14$ Torr's. When $T_{\text {dep }}$ is lowered further to $80{ }^{\circ} \mathrm{C}$, $\mathrm{AlO}_{x}$ nucleation becomes completely nonpreferential, nucleating almost everywhere on the $\mathrm{G} / \mathrm{Cu}$ surface and yielding a surface coverage $(\theta)$ of $\sim 98 \%$. Note that the nonpreferential nucleation is not due to the effect of insufficient purging because a too short $t_{\text {pur }}$ will result in premature hydrolysis of TMA, which impedes $\mathrm{AlO}_{x}$ nucleation on graphene (see also the Supporting Information, section SI3). Instead, the very smooth surface topography of the $\mathrm{AlO}_{x}$-covered graphene with a rms surface roughness of $<1 \mathrm{~nm}$ and barely visible $\mathrm{G} / \mathrm{Cu}$ surface features indicates that the troughs are covered by $\mathrm{AlO}_{x}$ more than the ridges. This strongly suggests the occurrence of $\mathrm{H}_{2} \mathrm{O} /$ TMA condensation when ALD is performed at $80{ }^{\circ} \mathrm{C}$. The use of noncondensing $\mathrm{O}_{3}$ replacing $\mathrm{H}_{2} \mathrm{O}$ as the oxidant at a
$T_{\text {dep }}$ of $80{ }^{\circ} \mathrm{C}$ is shown in Figure $3 \mathrm{~b}$. In contrast to the nucleation obtained using $\mathrm{H}_{2} \mathrm{O}$ at a $T_{\text {dep }}$ of $80{ }^{\circ} \mathrm{C}$, that using $\mathrm{O}_{3}$ yields a moderately preferential nucleation on the ridges with $\theta$ of $\sim 65 \%$. The correlation between $\theta$ and $T_{\text {dep }}$ in $C M$ is shown in Figure $3 \mathrm{~d}$. In general, a relatively constant $\theta$ at an average value of $79-82 \%$ can be achieved in CM with $T_{\text {dep }}$ of $120-180$ ${ }^{\circ} \mathrm{C}$ using $\mathrm{H}_{2} \mathrm{O} / \mathrm{TMA}$. A condensing condition occurs at a $T_{\text {dep }}$ of $80{ }^{\circ} \mathrm{C}$, resulting in almost complete coverage of $\mathrm{AlO}_{x}$. On the other side of the spectrum, a $T_{\text {dep }}$ of $200{ }^{\circ} \mathrm{C}$ is always observed to yield the lowest $\mathrm{AlO}_{x}$ coverage with $\theta \sim 43 \%$, although PM (Figure $1 \mathrm{~b}$ ) can be employed to improve $\theta$ as discussed below.

The fact that $\mathrm{CM}$ at a $T_{\text {dep }}$ of $200{ }^{\circ} \mathrm{C}$ yields the lowest $\mathrm{AlO}_{x}$ coverage gives rise to the assumption that the graphene surface needs to be uniformly activated by surface modification to obtain a more homogeneous nucleation if a $\mathrm{H}_{2} \mathrm{O} / \mathrm{TMA}$ combination is to be used at a high $T_{\text {dep }}{ }^{2,12,13,16,18}$ Because the use of an additional seed layer is undesirable because of its potential deleterious effect to the device functionality, surface modification is introduced in this study by the use of PM (Figure $1 \mathrm{~b}$ ), which is essentially an exposure to a series of $\mathrm{H}_{2} \mathrm{O}$ 


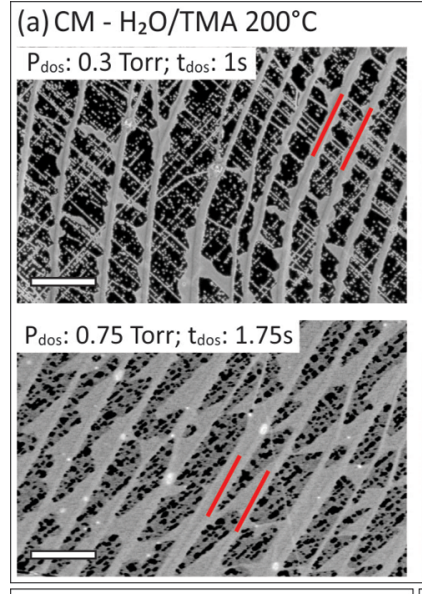

(b) $\mathrm{MM}-\mathrm{H}_{2} \mathrm{O} / \mathrm{TMA} 200^{\circ} \mathrm{C}$

$P_{\text {dos: }}: 0.45$ Torr; $\mathrm{t}_{\text {dos: }}: 2.5 \mathrm{~s}$
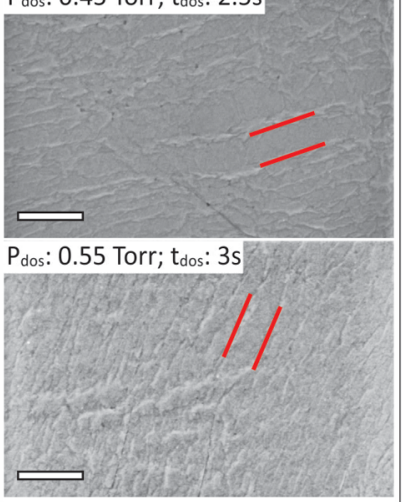

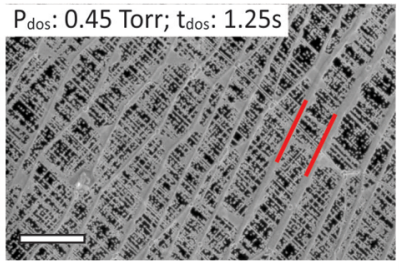

Pdos: 1.05 Torr; tos: $2 \mathrm{~s}$

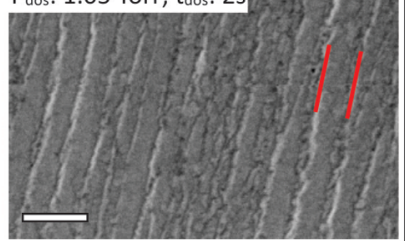

(c) $\mathrm{SM}-\mathrm{H}_{2} \mathrm{O} / \mathrm{TMA} 200^{\circ} \mathrm{C}$

$P_{\text {dos: }}$ : 0.2 Torr; $\mathrm{t}_{\mathrm{dos}}: 3.5 \mathrm{~s}$

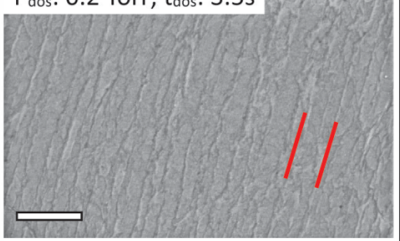

Pdos: $_{0.2}$ Torr; $\mathrm{t}_{\text {dos }}$ : $3.5 \mathrm{~s}$

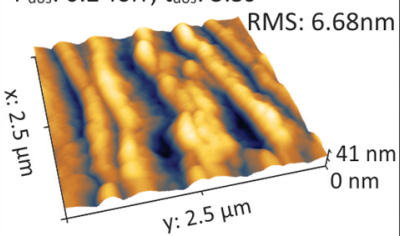

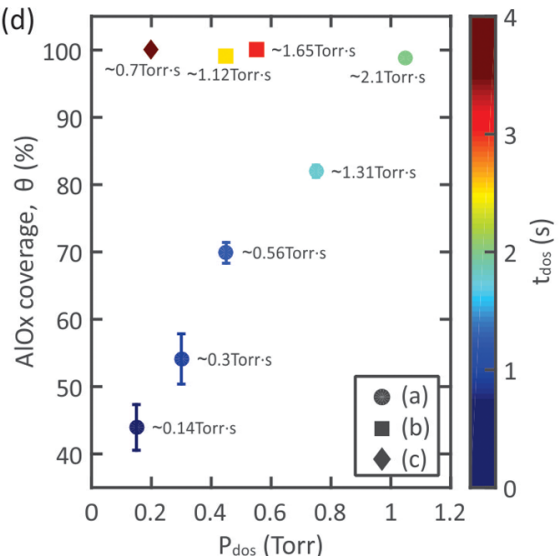

(e)

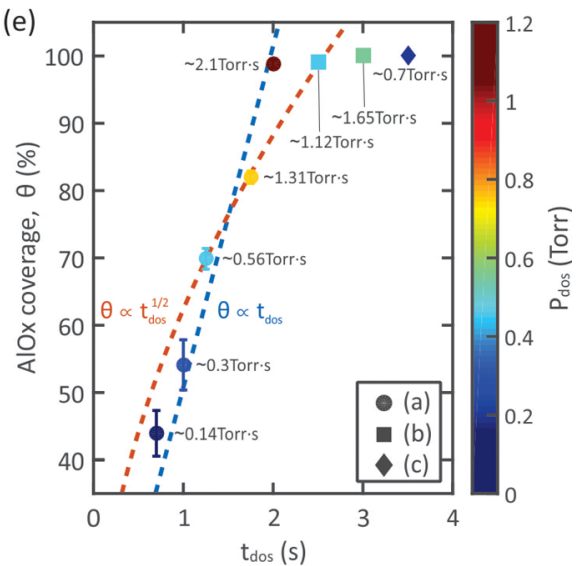

Figure 4. (a) $\mathrm{AlO}_{x}$ nucleation by ALD in CM at a $T_{\text {dep }}$ of $200{ }^{\circ} \mathrm{C}$ using increasing doses of $\mathrm{H}_{2} \mathrm{O} / \mathrm{TMA}$. Although the nucleation is still highly preferential to the ridges, an increase in the $\mathrm{H}_{2} \mathrm{O}$ /TMA dose significantly improves the $\mathrm{AlO}_{x}$ nucleation especially on the troughs of $\mathrm{G} / \mathrm{Cu}$, which leads to a higher $\theta$. Full $\mathrm{AlO}_{x}$ coverage is obtained using a $\mathrm{H}_{2} \mathrm{O} / \mathrm{TMA}$ dose of $\sim 2.1$ Torr's $\left(P_{\text {dos }}=\sim 1.05\right.$ Torr; $\left.t_{\text {dos }}=\sim 2 \mathrm{~s}\right)$. The typical $\mathrm{H}_{2} \mathrm{O} / \mathrm{TMA}$ dose used in Figures 2 and 3 is $\sim 0.14$ Torr.s $\left(P_{\text {dos }}=\sim 0.2\right.$ Torr; $\left.t_{\text {dos }}=\sim 0.7 \mathrm{~s}\right)$. A homogeneous $\mathrm{AlO}_{x}$ nucleation on G/Cu using $\mathrm{H}_{2} \mathrm{O} / \mathrm{TMA}$ at a $T_{\text {dep }}$ of $200{ }^{\circ} \mathrm{C}$ can also be achieved by performing ALD either in MM (b) or in SM (c). Under either one of these modes, the $\mathrm{H}_{2} \mathrm{O} / \mathrm{TMA}$ residence time $\left(t_{\text {dos }}\right)$ could be extended to reach complete $\mathrm{AlO}_{x}$ coverage without necessarily increasing the $\mathrm{H}_{2} \mathrm{O} / \mathrm{TMA}$ dose pressure $\left(P_{\text {dos }}\right)$. Full $\mathrm{AlO}_{x}$ coverage can be observed in part $\mathrm{b}$ when the $\mathrm{H}_{2} \mathrm{O} / \mathrm{TMA}$ dose is at $\sim 1.65$ Torr $\cdot \mathrm{s}\left(P_{\text {dos }}=\sim 0.55\right.$ Torr; $\left.t_{\text {dos }}=\sim 3 \mathrm{~s}\right)$ in MM and in part $\mathrm{c}$ at $\sim 0.7$ Torr $\cdot \mathrm{s}\left(P_{\text {dos }}=\sim 0.2\right.$ Torr; $t_{\text {dos }}=\sim 3.5 \mathrm{~s}$ ) in SM. The $\mathrm{AlO}_{x}$ surface topography in part $\mathrm{c}$ is similar to that of as-grown $\mathrm{G} / \mathrm{Cu}$, suggesting a conformal deposition. Plot of $\theta$ on the G/Cu surface by ALD in CM, MM, and SM as a function of $P_{\text {dos }}(\mathrm{d})$ and $t_{\mathrm{dos}}(\mathrm{e})$. In part $\mathrm{d}$, the color of the marker indicates $t_{\mathrm{dos}}$, while in part e, it indicates $P_{\text {dos }}$. In general, the relationship between $\theta$ and $t_{\text {dos }}$ is linear, i.e., $\theta \propto t_{\text {dos, }}$ instead of the square root, $\theta \propto t_{\text {dos }}{ }^{1 / 2}$, until a saturation is reached at $t_{\mathrm{dos}} \geq \sim 3 \mathrm{~s}$. In parts a-c, all scale bars represent $500 \mathrm{~nm}$ and the red parallel lines indicate the ridges of $\mathrm{G} / \mathrm{Cu}$ surface features, and the error bars in parts $\mathrm{d}$ and $\mathrm{e}$ indicate the standard deviation from the mean. All $\mathrm{AlO}_{x}$ depositions are performed with $12 \mathrm{ALD}$ cycles total.

or $\mathrm{O}_{3}$ pulses for a certain period of pretreatment time $\left(t_{\text {pretreat }}\right)$, followed immediately by a $\mathrm{AlO}_{x}$ deposition that is similar to $\mathrm{CM}$ without breaking the vacuum. Aside from the additional pretreatment step, the deposition parameters in PM are set to be the same as those in the aforementioned $\mathrm{CM}$, i.e., using a TMA $/ \mathrm{H}_{2} \mathrm{O}$ dose of $\sim 0.14$ Torr $\cdot \mathrm{s}$ at a $T_{\text {dep }}$ of $200{ }^{\circ} \mathrm{C}$. Figure $3 \mathrm{c}$ shows that a substantial shift in the $\mathrm{AlO}_{x}$ nucleation behavior is observed when $t_{\text {pretreat }}$ is set at $60 \mathrm{~min}$, with the nucleation is no longer preferential to the graphene ridges but rather distributed evenly between both ridges and troughs. The change in the nucleation behavior is more pronounced when $t_{\text {pretreat }}$ is prolonged further to $300 \mathrm{~min}$, at which point the nucleation is significantly more homogeneous throughout the $\mathrm{G} / \mathrm{Cu}$ surface. Similarly, the switch from $\mathrm{CM}$ to $\mathrm{PM}$ when $\mathrm{O}_{3}$ is used as the oxidant not only results in a significant improvement to the nucleation density but also completely changes the nucleation behavior, as shown in Figure $3 \mathrm{~d}$. With a $t_{\text {pretreat }}$ of just $2 \mathrm{~min}$, the nucleation becomes completely nonpreferential and a highly conformal $\mathrm{AlO}_{x}$ layer is observed throughout the $\mathrm{G} / \mathrm{Cu}$ surface. It is also important to note that the nucleation in the troughs is always found to be much more homogeneous than that on the ridges whenever $\mathrm{O}_{3}$ pretreatment is used. The correlation between $\theta$ and $t_{\text {pretreat }}$ in PM is shown in Figure $3 \mathrm{f}$. In general, the use of PM improves the $\mathrm{AlO}_{x}$ coverage on G/ $\mathrm{Cu}$, where $\theta$ increases proportionally with an increase of $t_{\text {pretreat }}$. While improvement is observed regardless of whether $\mathrm{H}_{2} \mathrm{O}$ vapor or $\mathrm{O}_{3}$ is used as the oxidant, the effect is much more pronounced for the latter for a short $t_{\text {pretreat }}$. Using $\mathrm{O}_{3} / \mathrm{TMA}$, a significant improvement in $\theta$ to $\sim 96 \%$ can be observed for a $t_{\text {pretreat }}$ of just $2 \mathrm{~min}$, although a further increase of $t_{\text {pretreat }}$ to 15 min only increases $\theta$ slightly to $\sim 97 \%$. In contrast, using $\mathrm{H}_{2} \mathrm{O}$ / TMA, a significant improvement in $\theta$ to $\sim 89 \%$ can only be observed when $t_{\text {pretreat }}$ is set to $300 \mathrm{~min}$. Because all deposition parameters in PM are exactly the same as those in CM, the observed changes in the otherwise preferential $\mathrm{AlO}_{x}$ nucleation can all be attributed to the addition of the pretreatment step.

Previous literature has already highlighted that ALD $\mathrm{AlO}_{x}$ nucleation on MLG can be highly dependent on the underlying graphene support/substrate. ${ }^{17}$ Here we observe that, for fewlayer graphene, it is also dependent on the number of graphene 
layers. As shown in Figure 3d,f, the nucleation density in the troughs of MLG is considerably higher than that in the troughs of bilayer graphene (BLG). While the use of PM, either with $\mathrm{H}_{2} \mathrm{O}$ or $\mathrm{O}_{3}$, results in a more homogeneous $\mathrm{AlO}_{x}$ nucleation on MLG, the nucleation on BLG is still highly selective. When PM is performed using $\mathrm{H}_{2} \mathrm{O}$ with a $t_{\text {pretreat }}$ of $60 \mathrm{~min}, \mathrm{AlO}_{x}$ shows very poor nucleation in the troughs of BLG, resulting in an extremely low $\theta$ of $\sim 33 \%$, approximately half that on MLG (Figure 3f). A significant improvement to the $\mathrm{AlO}_{x}$ nucleation on BLG can be achieved by extending $t_{\text {pretreat }}$ to $300 \mathrm{~min}$. This results not only in an increase of $\theta$ on BLG to $\sim 79 \%$ (Figure 3f) but also in a shift of the $\mathrm{AlO}_{x}$ nucleation behavior to a more homogeneous nucleation on both ridges and troughs. While a higher $\theta$ can be, in general, achieved using $\mathrm{O}_{3}$ with a $t_{\text {pretreat }}$ of 2 min, the $\mathrm{AlO}_{x}$ nucleation density in the troughs of BLG is still much lower than that in the troughs of MLG. Note that the nucleation behavior on the ridges is unaffected by the number of graphene layers, as observed from the constant nucleation density on the ridges across the MLG-BLG boundaries.

The failure of PM to achieve conformal $\mathrm{AlO}_{x}$ nucleation on $\mathrm{G} / \mathrm{Cu}$ using $\mathrm{H}_{2} \mathrm{O} / \mathrm{TMA}$ at a $T_{\text {dep }}$ of $200{ }^{\circ} \mathrm{C}$ motivates us here to investigate in more detail the limiting parameters at such a high $T_{\text {dep }}$. Because ALD depends heavily on surface saturation to achieve the self-limiting reactions, there is a possibility that the aforementioned selective $\mathrm{AlO}_{x}$ nucleation on graphene is due to unsatisfied saturation conditions, and it is unclear in the literature whether these conditions are always satisfied. Thus, we explore the use of higher $\mathrm{H}_{2} \mathrm{O}$ /TMA doses than the commonly used dose, with the aim of achieving surface saturation to obtain conformal $\mathrm{AlO}_{x}$ nucleation on graphene. The improvement in the nucleation density under $\mathrm{CM}$ at a $T_{\text {dep }}$ of $200{ }^{\circ} \mathrm{C}$ due to the use of higher $\mathrm{H}_{2} \mathrm{O}$ /TMA doses is shown in Figure 4a. While increasing the $\mathrm{H}_{2} \mathrm{O}$ /TMA dose from $\sim 0.14$ to $\sim 0.3$ and $\sim 0.56$ Torr.s substantially increases the nucleation density in the troughs, the nucleation behavior itself is relatively unaltered, i.e., is still highly preferential to the ridges, suggesting that the nucleation behavior cannot be easily altered by exclusively changing the $\mathrm{H}_{2} \mathrm{O}$ /TMA dose. Note that the $\mathrm{AlO}_{x}$ nucleation on the troughs at such a higher dose always results in a crisscrossed pattern. A transition in the nucleation behavior toward nonpreferential nucleation can be observed once the $\mathrm{H}_{2} \mathrm{O} /$ TMA dose is increased further to $\sim 1.31$ Torr.s, and consequently an even higher $\mathrm{H}_{2} \mathrm{O}$ /TMA dose of $\sim 2.1$ Torr.s results in a conformal nucleation of $\mathrm{AlO}_{x}$. This finding suggests that conformal nucleation on graphene at high $T_{\text {dep }}$ is attainable if the $\mathrm{H}_{2} \mathrm{O}$ /TMA dose is sufficient to achieve surface saturation.

Given that the oxidant/precursor dose is essentially a product of the delivery pressure $\left(P_{\text {dos }}\right)$ and residence time $\left(t_{\text {dos }}\right)$, a sufficiently high dose for conformal nucleation can be obtained by a higher $P_{\text {dos }}$ and/or a longer $t_{\text {dos }}$. Because it is not trivial to explore the effect of each parameter in CM because of the interdependence of $P_{\text {dos }}$ and $t_{\text {dos }}$, i.e., both are controlled by a single-parameter oxidant/precursor pulse time $\left(t_{\text {pul }}\right)$, we introduce modifications to the ALD process, denoted herein as MM and SM, which allow us to decouple $t_{\text {dos }}$ from $P_{\text {dos. }}$. In MM (Figure 1c), each $\mathrm{H}_{2} \mathrm{O}$ /TMA dose is delivered by a sequence of two consecutive pulses in quick succession such that $t_{\text {dos }}$ is now controlled by the interval time between pulses $\left(t_{\text {interv }}\right)$ rather than by $t_{\text {pul }}$. Thus, MM allows $t_{\text {dos }}$ to be extended to about twice as long as that in $\mathrm{CM}$ without changing $P_{\text {dos }}$. In SM (Figure $1 \mathrm{~d})$, the sample is soaked in a $\mathrm{H}_{2} \mathrm{O}$ /TMA dose for several seconds $\left(t_{\text {hold }}\right.$ ) before being purged, allowing $t_{\text {dos }}$ to be controlled by $t_{\text {hold }}$ rather than by $t_{\text {pul }}$. Thus, SM allows $t_{\text {dos }}$ to be completely independent from $P_{\text {dos }}$ and extended virtually indefinitely. The use of MM and SM ALD to obtain a conformal $\mathrm{AlO}_{x}$ nucleation on $\mathrm{G} / \mathrm{Cu}$ at a $T_{\text {dep }}$ of $200{ }^{\circ} \mathrm{C}$ is shown in Figure $4 \mathrm{~b}, \mathrm{c}$. A completely nonpreferential nucleation can be easily obtained with a $\mathrm{H}_{2} \mathrm{O} / \mathrm{TMA}$ dose of $\sim 1.12$ Torr.s, and a further increase in the $\mathrm{H}_{2} \mathrm{O} / \mathrm{TMA}$ dose to $\sim 1.65$ Torr.s results in a highly homogeneous $\mathrm{AlO}_{x}$ nucleation with complete surface coverage. Similarly, a highly homogeneous nucleation can be achieved by performing ALD in SM with a $\mathrm{H}_{2} \mathrm{O}$ /TMA dose of just $\sim 0.7$ Torr.s. The similarity in the surface topography between $\mathrm{AlO}_{x}$ deposited under SM and bare G/ $\mathrm{Cu}$ suggests that the deposition is highly conformal.

The correlation between $\theta$ and $P_{\text {dos }}$ for CM, MM, and SM is shown in Figure $4 \mathrm{~d}$, while the correlation between $\theta$ and $t_{\text {dos }}$ is shown in Figure 4e. Although the relationship between $\theta$ and $P_{\text {dos }}$ is observed to be approximately linear for just CM, because an increase in the dose from $\sim 0.14$ Torr $\cdot s$ (typical dose) to $\sim 2.1$ Torr.s results in an increase of $\theta$ from $\sim 44 \%$ to $\sim 99 \%$, the overall correlation becomes extremely poor once the nucleation under MM and SM is taken into account. In contrast, a strong linear correlation between $\theta$ and $t_{\mathrm{dos}}$ can be observed for all ALD modes because a higher $t_{\text {dos }}$ results in a higher $\theta$ until saturation is achieved at $t_{\text {dos }} \geq \sim 2 \mathrm{~s}$. It is important to note that a conformal $\mathrm{AlO}_{x}$ nucleation is obtained with just $12 \mathrm{ALD}$ cycles in MM and SM with a $\mathrm{H}_{2} \mathrm{O} / \mathrm{TMA}$ dose of $<1.3$ Torr.s, whereas the same dose in $\mathrm{CM}$ results in a nucleation behavior that is still preferential with a $\theta$ of only $\sim 82 \%$.

Here we also explore the use of SM to achieve conformal $\mathrm{AlO}_{x}$ nucleation at a $T_{\text {dep }}$ of $200{ }^{\circ} \mathrm{C}$ on HOPG, G/Ge, and G/ $\mathrm{SiO}_{2}$. These graphitic surfaces are known to be much less wettable by $\mathrm{H}_{2} \mathrm{O}$ than $\mathrm{G} / \mathrm{Cu} \cdot{ }^{17,24}$ Comparisons in the nucleation behavior between CM and SM at the same $T_{\text {dep }}$ on these surfaces are shown in Figure $5 \mathrm{a}-\mathrm{c} . \mathrm{AlO}_{x}$ nucleation on HOPG under CM at a $T_{\text {dep }}$ of $200{ }^{\circ} \mathrm{C}$ and a $\mathrm{H}_{2} \mathrm{O} / \mathrm{TMA}$ dose of $\sim 0.3$ Torr.s $\left(P_{\text {dos }}=\sim 0.3\right.$ Torr; $\left.t_{\text {dos }}=\sim 1 \mathrm{~s}\right)$ results in incomplete surface coverage with a relatively low $\theta$ of $\sim 68 \%$. Despite the low $\theta$, the nucleation on HOPG appears to be random and nonselective to only specific sites (Figure 5a). On the other hand, when $\mathrm{CM}$ is performed on $\mathrm{G} / \mathrm{Ge}$ and $\mathrm{G} / \mathrm{SiO}_{2}$ under the same conditions, $\mathrm{AlO}_{x}$ nucleates selectively on specific, more highly reactive locations, resulting in an extremely low $\theta$ of just $\sim 47 \%$ (Figure $5 b$ ) and $\sim 38 \%$ (Figure $5 \mathrm{c})$, respectively. Although it is more spatially irregular than that on $\mathrm{G} / \mathrm{Cu}, \mathrm{AlO}_{x}$ nucleation on $\mathrm{G} / \mathrm{SiO}_{2}$ is observed to be highly selective to the randomly oriented graphene folding and defect sites (Figure 5c). Currently, the most common transfer method used leads to the removal of uniaxial surface features that occur ubiquitously on $\mathrm{G} / \mathrm{Cu}$ but at the expense of introducing new reactive sites, including folding sites, defects, and contamination, to the graphene. As a result, $\mathrm{AlO}_{x}$ appears to nucleate preferentially on these newly introduced reactive sites. Similarly, the absence of graphene wrinkles and folding sites on $\mathrm{G} / \mathrm{Ge}$ suggests that the nucleation is now preferential to domain boundaries and defect sites (Figure 5b). On the other hand, the nucleation under SM at a $T_{\text {dep }}$ of $200{ }^{\circ} \mathrm{C}$ and a $\mathrm{H}_{2} \mathrm{O} / \mathrm{TMA}$ dose of $\sim 0.7$ Torr's $\left(P_{\text {dos }}=\sim 0.2\right.$ Torr; $t_{\text {dos }}=\sim 3.5$ $\mathrm{s})$ is much more homogeneous across the entire surface, resulting in $\mathrm{AlO}_{x}$ coverage with $\theta>97 \%$ on all samples (Figure $5 \mathrm{a}-\mathrm{c}$ ). Such a homogeneous nucleation allows the formation of sub-2-nm thin continuous $\mathrm{AlO}_{x}$ films, as measured by $\mathrm{AFM}$ (see also the Supporting Information, section SI4), with just 12 ALD cycles. In terms of the dielectric quality, these continuous $\mathrm{AlO}_{x}$ films exhibit capacitance values of 1.6 and $0.7 \mu \mathrm{F} / \mathrm{cm}^{2}$ and 

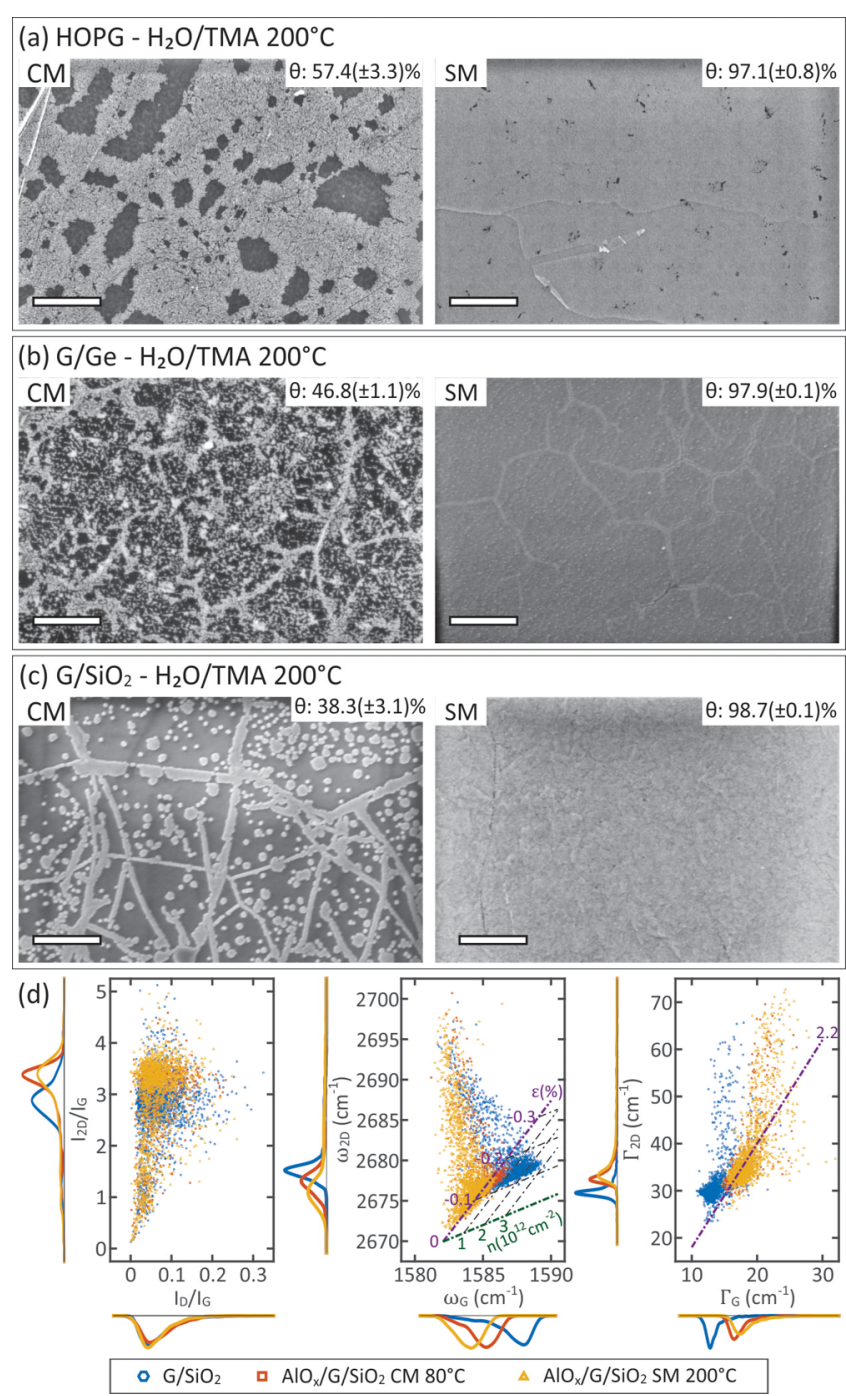

Figure 5. $\mathrm{AlO}_{x}$ nucleation on $\mathrm{HOPG}(\mathrm{a}), \mathrm{G} / \mathrm{Ge}(\mathrm{b})$, and $\mathrm{G} / \mathrm{SiO}_{2}$ (c) by ALD in CM at a $T_{\text {dep }}$ of $200{ }^{\circ} \mathrm{C}$ using a $\mathrm{H}_{2} \mathrm{O} / \mathrm{TMA}$ dose of $\sim 0.3$ Torr $\cdot \mathrm{s}\left(P_{\text {dos }}=\sim 0.3\right.$ Torr; $\left.t_{\text {dos }}=\sim 1 \mathrm{~s}\right)$ for 48 cycles total and under SM at a $T_{\text {dep }}$ of $200{ }^{\circ} \mathrm{C}$ using a $\mathrm{H}_{2} \mathrm{O} / \mathrm{TMA}$ dose of $\sim 0.8$ Torr $\cdot \mathrm{s}\left(P_{\text {dos }}=\right.$ $\sim 0.2$ Torr; $t_{\text {dos }}=\sim 4 \mathrm{~s}$ ) for 12 cycles total. The use of $\mathrm{CM}$ yields a relatively low surface coverage of $\sim 57 \%$ on HOPG (a), $47 \%$ on G/ $\mathrm{Ge}(\mathrm{b})$, and $\sim 38 \%$ on $\mathrm{G} / \mathrm{SiO}_{2}$ (c). In contrast to the nucleation behavior on HOPG, which is relatively nonpreferential, that on $\mathrm{G} / \mathrm{Ge}$ and $\mathrm{G} / \mathrm{SiO}_{2}$ is preferential to the more active locations, e.g., domain boundaries, folding sites, and contaminations, introduced by the transfer process. The use of SM results in an almost perfectly conformal $\mathrm{AlO}_{x}$ nucleation with surface coverage of $>97 \%$ on all samples. All scale bars in parts a-c represent $500 \mathrm{~nm}$. (d) Raman spectroscopy analysis of $\mathrm{G} / \mathrm{SiO}_{2}$ samples before and after ALD using a photon excitation of $532 \mathrm{~nm}$. The analysis is represented by a plot of the $2 \mathrm{D}$ and $\mathrm{G}$ peak intensity ratio $\left(I_{2 \mathrm{D}} / I_{\mathrm{G}}\right)$ against the $\mathrm{D}$ and $\mathrm{G}$ peak intensity ratio $\left(I_{\mathrm{D}} / I_{\mathrm{G}}\right)$, a plot of the $2 \mathrm{D}$ peak position $\left(\omega_{2 \mathrm{D}}\right)$ against the $\mathrm{G}$ peak position $\left(\omega_{\mathrm{G}}\right)$ including an indication of the relative strain and doping contributions, and a plot of the $2 \mathrm{D}$ peak line width $\left(\Gamma_{2 \mathrm{D}}\right)$ against the $\mathrm{G}$ peak line width $\left(\Gamma_{\mathrm{G}}\right)$.

leakage currents of lower than $1 \mathrm{nA}$ at 0.7 and $2.2 \mathrm{~V}$ when ALD is performed in SM with a $\mathrm{H}_{2} \mathrm{O} / \mathrm{TMA}$ dose of $\sim 0.7$ Torr.s for 20 and 50 ALD cycles, respectively (see also the Supporting Information, section SI5). The agreement between these values and those of $\mathrm{AlO}_{x}$ formation on graphene found in the literature strongly suggests that the $\mathrm{AlO}_{x}$ films deposited under $\mathrm{SM}$ are indeed continuous and have the potential to act as an efficient high- $\kappa$ dielectric in graphene electronics with EOT < $1.3 \mathrm{~nm} .{ }^{23,36}$ The fact that the difference between $\mathrm{CM}$ and SM used here is only in $t_{\text {dos }}$, i.e., $t_{\text {dos }}$ in SM, more than 3 times as long as that in CM accentuates the importance of a longer $t_{\text {dos }}$ for obtaining homogeneous $\mathrm{AlO}_{x}$ nucleation.

Figure 5d shows the effect of $\mathrm{AlO}_{x}$ film deposition on graphene analyzed by Raman spectroscopy on $\mathrm{G} / \mathrm{SiO}_{2}$ prior and subsequent to ALD using $532 \mathrm{~nm}$ excitation (see also the Supporting Information, section SI6, for individual representative Raman spectra). The peak intensity ratio of the $2 \mathrm{D}$ and $\mathrm{G}$ bands $\left(I_{2 \mathrm{D}} / I_{\mathrm{G}}\right)$ is found at $\sim 2.88$ for as-transferred $\mathrm{G} / \mathrm{SiO}_{2}$ and shifts toward a higher value of $\sim 3.39$ after $\mathrm{AlO}_{x}$ deposition $\left(\mathrm{AlO}_{x} / \mathrm{G} / \mathrm{SiO}_{2}\right)$ for both CM and SM. Note that here CM is performed using a $\mathrm{H}_{2} \mathrm{O} / \mathrm{TMA}$ dose of 0.3 Torr's at a $T_{\text {dep }}$ of 80 ${ }^{\circ} \mathrm{C}$, while $\mathrm{SM}$ is performed using a $\mathrm{H}_{2} \mathrm{O} / \mathrm{TMA}$ dose of 0.7 Torr's at a $T_{\text {dep }}$ of $200{ }^{\circ} \mathrm{C}$, and both yield almost complete $\mathrm{AlO}_{x}$ coverage with $\theta>98 \%$ on $\mathrm{G} / \mathrm{SiO}_{2}$. The Raman peak intensity ratio between the $\mathrm{D}$ and $\mathrm{G}$ bands $\left(I_{\mathrm{D}} / I_{\mathrm{G}}\right)$ is $\sim 0.04$ for the astransferred $\mathrm{G} / \mathrm{SiO}_{2}$ samples and remains the same for $\mathrm{AlO}_{x} / \mathrm{G} /$ $\mathrm{SiO}_{2}$ regardless of the ALD mode used. For the as-transferred $\mathrm{G} / \mathrm{SiO}_{2}$, the peak frequencies of the $2 \mathrm{D}\left(\omega_{2 \mathrm{D}}\right)$ and $\mathrm{G}\left(\omega_{\mathrm{G}}\right)$ bands are found at $\sim 2679$ and $\sim 1588 \mathrm{~cm}^{-1}$, respectively, with a $\omega_{2 \mathrm{D}} / \omega_{\mathrm{G}}$ slope of $\sim 0.7$. When ALD is performed in CM, $\omega_{2 \mathrm{D}}$ and $\omega_{\mathrm{G}}$ are found at $\sim 2677$ and $\sim 1585 \mathrm{~cm}^{-1}$, respectively, while when ALD is performed in SM, they are found at $\sim 2676$ and $\sim 1584 \mathrm{~cm}^{-1}$, respectively. Note that the $\omega_{2 \mathrm{D}} / \omega_{\mathrm{G}}$ slope shifts to $\sim 2.2$ for $\mathrm{AlO}_{x} / \mathrm{G} / \mathrm{SiO}_{2}$ regardless of the ALD mode used. The line widths of the $2 \mathrm{D}\left(\Gamma_{2 \mathrm{D}}\right)$ and $\mathrm{G}\left(\Gamma_{\mathrm{G}}\right)$ bands are found at $29.5( \pm 5.3)$ and $12.8( \pm 1.5) \mathrm{cm}^{-1}$, respectively, for the as-transferred $\mathrm{G} / \mathrm{SiO}_{2}$ and shift toward higher values after $\mathrm{AlO}_{x}$ deposition. When ALD is performed in CM, $\Gamma_{2 \mathrm{D}}$ and $\Gamma_{\mathrm{G}}$ are found to be broadened to $32.3( \pm 6.9)$ and $16.4( \pm 1.8)$ $\mathrm{cm}^{-1}$, respectively, while when ALD is performed in SM, they are further broadened to $33.1( \pm 7.7)$ and $17.2( \pm 2.1) \mathrm{cm}^{-1}$, respectively. The $\Gamma_{2 \mathrm{D}} / \Gamma_{\mathrm{G}}$ slope is $\sim 2.2$ for all $\mathrm{G} / \mathrm{SiO}_{2}$ samples, with or without ALD $\mathrm{AlO}_{x}$.

\section{DISCUSSION}

Our data show that the deposition of $\mathrm{AlO}_{x}$ on $\mathrm{G} / \mathrm{Cu}$ using a typical ALD process, i.e., CM at a $T_{\text {dep }}$ of $200{ }^{\circ} \mathrm{C}$ and a TMA/ $\mathrm{H}_{2} \mathrm{O}$ dose of $\sim 0.14$ Torr $\cdot \mathrm{s}$, is strongly affected by the presence of uniaxial $\mathrm{G} / \mathrm{Cu}$ surface features, where the ridges form preferential $\mathrm{AlO}_{x}$ nucleation sites. These ridges are the topographically highest points on the $\mathrm{G} / \mathrm{Cu}$ surface, making them more readily available sites for adsorption of the oxidant/ precursor. More importantly, the high curvature of the ridges is known to present the most active sites on supported graphene because of the high strain in the $\mathrm{C}-\mathrm{C}$ bonds. ${ }^{27,37,38}$ Similar to the nucleation on line defects and step edges, the nucleation on these ridges has long been thought to be energetically preferable to the release strain and ultimately relaxes the graphene. ${ }^{34,37} \mathrm{AlO}_{x}$ deposition in the troughs themselves does not take place within the first few ALD cycles but rather starts to occur several tens of cycles later once the ridges, i.e., the most reactive sites, have been fully occupied and passivated by $\mathrm{AlO}_{x}$ clusters (Figure 2). ${ }^{14,34}$ The highly selective nucleation behavior at such a high $T_{\text {dep }}$ has led the hitherto conclusion in the literature that conformal $\mathrm{AlO}_{x}$ nucleation on a graphitic surface using the standard $\mathrm{H}_{2} \mathrm{O}$ /TMA precursor is notoriously difficult to achieve, and thus a lower $T_{\text {dep }}$ or a surface modification that promotes uniform wetting is required. $^{13-17,19,20,34,39}$ 
In terms of $T_{\text {dep }}$, it is widely known that an ideal ALD process can only occur in a very specific $T_{\text {dep }}$ window. ${ }^{39}$ A higher $T_{\text {dep }}$ provides sufficient thermal energy to drive the surface reaction to reach completion, although it may also lead to a higher desorption rate of oxidants/precursors from the $\mathrm{G} / \mathrm{Cu}$ surface, which results in a highly selective nucleation to only the reactive sites with lower $\theta$. On the other hand, a lower $T_{\text {dep }}$ often results in not only incomplete oxidant/precursor reactions ${ }^{33,35}$ but also the condensation of oxidants/precursors across the sample. ${ }^{39}$ As measured by spectroscopic ellipsometry (see the Supporting Information, section SI7), the refractive index of $\mathrm{AlO}_{x}$ films deposited at a $T_{\text {dep }}$ of $80^{\circ} \mathrm{C}$ is consistently lower, albeit only slightly, than that deposited at $200{ }^{\circ} \mathrm{C}$, suggesting that a lower $T_{\text {dep }}$ results in a lower density in the $\mathrm{AlO}_{x}$ films. ${ }^{16,40-42}$ In addition, the lower desorption rate at lower $T_{\text {dep }}$ corresponds to a longer ALD process time because of a longer purge time needed between pulses. ${ }^{40}$ Our data show that, in general, $\theta$ increases with a decrease of $T_{\text {dep }}$, where $T_{\text {dep }}$ of $120-180{ }^{\circ} \mathrm{C}$ yield an average $\theta$ of $79-75 \%$ and a $T_{\text {dep }}$ of 80 ${ }^{\circ} \mathrm{C}$ yields almost complete coverage with $\theta \sim 98 \%$ (Figure 3a). Thus, a lower $T_{\text {dep }}$ is definitely favorable if the goal is to alter the $\mathrm{AlO}_{x}$ deposition behavior so that deposition occurs everywhere across the $\mathrm{G} / \mathrm{Cu}$ surface. ${ }^{16,17}$ However, the fact that the resulting $\mathrm{AlO}_{x}$ layer is topographically very flat yet porous implies that the deposition is far from the ideal conformal deposition and is instead due to $\mathrm{H}_{2} \mathrm{O}$ condensation that takes place mostly in the troughs. The presence of $\mathrm{H}_{2} \mathrm{O}$ condensation at $80{ }^{\circ} \mathrm{C}$ can be confirmed by replacing it with $\mathrm{O}_{3}$ because $\mathrm{O}_{3}$ will still be gaseous and not condense at this temperature (Figure 3a). In contrast to the $\mathrm{AlO}_{x}$ nucleation using $\mathrm{H}_{2} \mathrm{O} / \mathrm{TMA}$, ALD with $\mathrm{O}_{3} / \mathrm{TMA}$ at the same $T_{\text {dep }}$ results in a much lower nucleation density with a $\theta$ of only $\sim 76 \%$ (Figure 3c,d). The absence of condensation is implied by the similarity in the $\mathrm{AlO}_{x}$ nucleation behavior between $\mathrm{O}_{3} / \mathrm{TMA}$ at a $\mathrm{T}_{\text {dep }}$ of $80^{\circ} \mathrm{C}$ and $\mathrm{H}_{2} \mathrm{O} / \mathrm{TMA}$ at a higher $T_{\text {dep }}$, i.e., preferential nucleation on the ridges. This implies that, as long as the noncondensing conditions are satisfied at low $T_{\text {dep }}$, the $\mathrm{AlO}_{x}$ nucleation behavior on $\mathrm{G} / \mathrm{Cu}$ under $\mathrm{CM}$ will always be selective to the most active sites, i.e., the ridges.

A modification to the graphitic surface is often introduced to make it more wettable, either by adding seed layers and functional groups, e.g., $\mathrm{Al}$ and PTCA, ${ }^{2,13}$ or by using a more reactive oxidant, e.g., $\mathrm{O}_{3}$ and $\mathrm{NO}_{2} \cdot{ }^{14,15,18}$ We here introduce a surface modification to the $\mathrm{G} / \mathrm{Cu}$ surface by performing ALD in PM to avoid the use of an undesirable additional seed layer and without the need to use a lower $T_{\text {dep }}$. When PM is performed using $\mathrm{H}_{2} \mathrm{O}$ /TMA, it has been suggested that $\mathrm{H}_{2} \mathrm{O}$ molecules are physically adsorbed onto the graphene surface by van der Waals forces during the pretreatment, which then act as nucleation sites for the subsequent ALD process. ${ }^{16,43}$ A higher density of nucleation sites can be, in principle, achieved with a longer $t_{\text {pretreat }}$ because it leads to a higher concentration of adsorbed $\mathrm{H}_{2} \mathrm{O}$ molecules on the $\mathrm{G} / \mathrm{Cu}$ surface. However, the intermolecular attraction between the $\mathrm{H}_{2} \mathrm{O}$ molecules may become increasingly dominant and exceed the van der Waals forces, resulting in island-like nucleation sites (Figure $3 \mathrm{~d}$ ). ${ }^{16}$ Our data indeed show that, at a $T_{\text {dep }}$ of $200{ }^{\circ} \mathrm{C}, \theta$ increases significantly with an increase of $t_{\text {pretreat }}$ despite the fact that the entire process becomes prohibitively long, taking about 300 min of pretreatment to reach a $\theta$ of $\sim 89 \%$ (Figure $3 \mathrm{f}$ ). An even more effective surface modification can be introduced by performing $\mathrm{PM}$ using $\mathrm{O}_{3}$. Because of its reactivity, $\mathrm{O}_{3}$ is commonly used to modify the graphene surface, either by cleaning the graphene surface or by functionalizing it with epoxide groups, ${ }^{14,15,44-46}$ to ultimately change the nucleation behavior into a highly homogeneous one. ${ }^{14,17,47}$ Indeed, a relatively short $t_{\text {pretreat }}$ of $2 \mathrm{~min}$ is sufficient to completely alter the $\mathrm{AlO}_{x}$ nucleation behavior completely nonselective (Figure 3f). Nevertheless, the use of $\mathrm{O}_{3} /$ TMA is less desirable because $\mathrm{O}_{3}$ is known to have a detrimental effect on graphene, especially at a high $T_{\text {dep }}{ }^{15}$ To minimize damage to the graphene, $T_{\text {dep }}$ is always set at $80{ }^{\circ} \mathrm{C}$ whenever $\mathrm{O}_{3}$ /TMA is used in this study. Nevertheless, even at such a low $T_{\text {dep }}$, the detrimental effects of $\mathrm{O}_{3}$ to the graphene structure could still be observed (see also the Supporting Information, section SI8). Therefore, a prolonged $\mathrm{O}_{3}$ pretreatment of more than $2 \mathrm{~min}$ should be avoided because it not only does not significantly improve the $\mathrm{AlO}_{x}$ nucleation density but also damages the graphene. In addition, the imposed upper $T_{\text {dep }}$ limit often results in a higher carbon concentration in the deposited $\mathrm{AlO}_{x}$ layer due to incomplete decomposition of the formate or other carboxylate species, ${ }^{48}$ which ultimately leads to a lower $\mathrm{AlO}_{x}$ density (see also the Supporting Information, section SI7).

While the use of PM allows a much more homogeneous $\mathrm{AlO}_{x}$ nucleation to be attained on monolayer G/Cu (MLG), it struggles to achieve the same nucleation density on bilayer G/ $\mathrm{Cu}$ (BLG). Our data show that while $\mathrm{AlO}_{x}$ nucleation on the ridges of the BLG is very similar to that on the ridges of the MLG, the nucleation density in the troughs of BLG is significantly lower than that of MLG. Interestingly, this behavior is always observed whether $\mathrm{H}_{2} \mathrm{O}$ or $\mathrm{O}_{3}$ is used as the oxidant, and although our observation is limited to only MLG and BLG, it suggests that $\mathrm{AlO}_{x}$ always nucleates preferentially on the ridges regardless of the number of graphene layers. The big difference in terms of the nucleation density in the troughs may originate from the difference in polarity between MLG and BLG, where a higher number of graphene layers corresponds to a lower surface polarity. ${ }^{17,24,49}$ It is important to note that the effect of the number of graphene layers is stronger when $\mathrm{O}_{3}$ is used as the oxidant rather than when $\mathrm{H}_{2} \mathrm{O}$ is used, although the difference between $\theta$ of MLG and BLG can be minimized by increasing $t_{\text {pretreat }}$. As shown by our data, such a difference can be minimized to $<10 \%$ after 300 min of pretreatment using $\mathrm{H}_{2} \mathrm{O}$ and to $<30 \%$ after 15 min of pretreatment using $\mathrm{O}_{3}$.

As in any gas-adsorption processes, the ALD process is known to be limited by the total amount of oxidant/precursor available for the reaction, quantified by the delivery pressure $\left(P_{\text {dos }}\right)$, as well as their mass transport to the surface and the surface reaction kinetics, both quantified by the residence time $\left(t_{\text {dos }}\right) .^{21,22}$ Thus, we hypothesize that a conformal $\mathrm{AlO}_{x}$ deposition can be, in principle, obtained using $\mathrm{H}_{2} \mathrm{O} / \mathrm{TMA}$ at a $T_{\text {dep }}$ of $200{ }^{\circ} \mathrm{C}$ by increasing $P_{\text {dos }}$ to compensate for a high desorption rate from the surface and/or by extending $t_{\text {dos }}$ to account for mass transport onto the imperfectly flat surface and slow adsorption kinetics of the relatively nonreactive graphitic surface. Our data indeed show that a higher $\mathrm{H}_{2} \mathrm{O}$ /TMA dose in $\mathrm{CM}$ always results in a higher $\mathrm{AlO}_{x}$ nucleation density, especially on the troughs, as reflected by an increase in $\theta$ from $\sim 44 \%$ to $\sim 82 \%$ when the dose is increased by an order of magnitude from $\sim 0.14$ to $\sim 1.31$ Torr $\cdot s$ (Figure $4 \mathrm{~d}$ ). Despite the significant increase in the nucleation density on the troughs due to the use of a remarkably high $\mathrm{H}_{2} \mathrm{O}$ /TMA dose, the nucleation behavior remains largely the same, i.e., preferential nucleation on the ridges. It is also important to note that the $\mathrm{AlO}_{x}$ nucleation in the troughs at a higher dose always results in 
a crisscrossed pattern (Figure 4a). While the origin of such a crisscrossed pattern is still unclear, we observe that one of the crisscrossed pattern axes is always aligned to the direction of the flow but independent of the direction of the graphene wrinkles and $\mathrm{Cu}$ surface reconstructions. This implies that the flow plays an important role in the nucleation behavior and may strongly affect oxidant/precursor mass transport to the $\mathrm{G} / \mathrm{Cu}$ surface. While an increase in $t_{\text {pul }}$ in CM always yields a higher dose due to a simultaneous increase of both $P_{\text {dos }}$ and $t_{\text {dos }}$, care must be taken because the relationship between them is not linear and is highly dependent on secondary ALD parameters including the carrier gas flow rate and pumping speed.

The use of MM and SM allows us here to decouple $t_{\text {dos }}$ from $P_{\text {dos }}$ such that a prolonged $t_{\text {dos }}$ could be achieved without necessarily increasing $t_{\mathrm{pul}}$ and consequently $P_{\mathrm{dos}}$. Typically, a prolonged $t_{\text {dos }}$ is employed to obtain conformal deposition on a high-aspect-ratio structure because a longer $t_{\text {dos }}$ is required for the oxidant/precursor molecules to fully diffuse into the structures. ${ }^{50}$ In fact, it has been estimated that the required $t_{\text {dos }}$ would be proportional to the square of the aspect ratio. ${ }^{22}$ Given that the aspect ratio of $\mathrm{G} / \mathrm{Cu}$ is much less than unity, we could argue that the diffusion of oxidant/precursor molecules onto the surface should not be a limiting factor. On the other hand, the long $t_{\text {dos }}$ may indeed be needed to account for the slow adsorption kinetics due to the inertness of the graphene surface. Our data show that, for the same $P_{\text {dos }}$, a longer , $\mathrm{t}_{\mathrm{dos}}$ results in a higher $\theta$, while for the same,$t_{\text {dos }}$, a higher, $\mathrm{P}_{\text {dos }}$ does not necessarily result in a higher $\theta$. In fact, when all data from CM, $\mathrm{MM}$, and SM are combined, $\theta$ can only be correlated to $t_{\mathrm{dos}}$ but not to $P_{\text {dos }}$. A strong correlation between $\theta$ and $t_{\text {dos }}$ is observed when $t_{\text {dos }}$ is less than a critical value of $\sim 2 \mathrm{~s}$, with $\theta$ varying linearly with $t_{\text {dos }}$, i.e., $\theta \propto t_{\text {dos }}$, instead of with the square root of $t_{\text {dos }}$, i.e., $\theta \propto t_{\text {dos }}^{1 / 2}$, suggesting that the ALD $\mathrm{AlO}_{x}$ on $\mathrm{G} / \mathrm{Cu}$ is surface-reaction-limited instead of diffusion-limited (Figure $4 \mathrm{e}) .{ }^{50}$ On the other hand, a saturation is reached, i.e., $\theta \approx$ $100 \%$, when $t_{\text {dos }} \geq \sim 2$ s regardless of the ALD mode used. In addition, the use of SM using $\mathrm{H}_{2} \mathrm{O} / \mathrm{TMA}$ with a $t_{\text {dos }}$ of $\sim 3.5 \mathrm{~s}$ allows a much more homogeneous nucleation with $\theta>97 \%$ to be obtained with just 12 ALD cycles on HOPG, G/Ge, and G/ $\mathrm{SiO}_{2}$ (Figure $5 \mathrm{a}-\mathrm{c}$ ), negating the difficulties in introducing conformal nucleation on the notoriously difficult-to-wet graphitic surfaces. It is important to note that the value of critical $t_{\text {dos }}$ may be different from one ALD system to another. It is also worth mentioning that the supporting substrates by themselves, e.g., bare $\mathrm{Cu}$ or $\mathrm{SiO}_{2}$ without graphene, are not difficult-to-wet surfaces, and thus homogeneous $\mathrm{AlO}_{x}$ nucleation could be consistently obtained with the typical parameters in CM (see also the Supporting Information, section SI9). While a conformal nucleation on these graphitic surfaces could still possibly be obtained by CM, a prohibitively high amount of $\mathrm{H}_{2} \mathrm{O} /$ TMA would probably be required. This finding strongly suggests that the $t_{\text {dos }}$ of $\mathrm{H}_{2} \mathrm{O}$ /TMA needed to obtain conformal nucleation at a $T_{\text {dep }}$ of $200{ }^{\circ} \mathrm{C}$ on graphitic surfaces is not excessively long. ${ }^{50}$ More importantly, this confirms our hypothesis that $t_{\text {dos }}$ is the key parameter to account for the slow adsorption kinetics of $\mathrm{H}_{2} \mathrm{O}$ /TMA on the relatively nonreactive graphitic surfaces; as such, the use of a lower $T_{\text {dep }}$ and the introduction of a surface modification are not a necessity for conformal $\mathrm{AlO}_{x}$ nucleation.

Raman analysis of $\mathrm{G} / \mathrm{SiO}_{2}$ before and after ALD $\mathrm{AlO}_{x}$ shows that the ALD process, in either CM or SM, does not introduce additional damage to the graphene structure, as reflected from their identical $I_{\mathrm{D}} / I_{\mathrm{G}}$ ratios. Thus, unlike the use of $\mathrm{O}_{3}$ as the oxidant, ${ }^{15}$ the use of $\mathrm{H}_{2} \mathrm{O}$ is relatively harmless for the graphene for a range of $T_{\text {dep }}$ values from 80 to $200{ }^{\circ} \mathrm{C}$. We also show here that $t_{\text {dos }}$ could be extended by up to $3.5 \mathrm{~s}$ in $\mathrm{SM}$ without introducing a detrimental effect to the graphene even at a high $T_{\text {dep. }}$. Nevertheless, care must be taken when an extremely long $t_{\text {dos }}$ is used because TMA is highly reactive and may result in the undesirable formation of defects on the graphene (see also the Supporting Information, section SI10).

Although nucleation on the ridges has long been thought to be energetically preferable to release the strains and ultimately relax the graphene, ${ }^{34,37}$ the effect of $\mathrm{AlO}_{x}$ nucleation on the mechanical strain is observed to be much less pronounced compared to its effect on charge doping of the graphene. The decrease in $\omega_{2 \mathrm{D}}$ and $\omega_{\mathrm{G}}$ modes toward lower wavenumbers indicates a decrease in the graphene doping level from $\sim 3 \times$ $10^{12}$ to $\sim 10^{12} \mathrm{~cm}^{-2}$ when $\mathrm{AlO}_{x}$ is introduced under $\mathrm{CM}$ at 80 ${ }^{\circ} \mathrm{C}$, while the mechanical strain level remains similar in magnitude between -0.1 and $-0.2 \%$ (Figure $5 \mathrm{~d}$ ). ${ }^{51,52}$ On the other hand, when $\mathrm{AlO}_{x}$ is deposited under $\mathrm{SM}$ at $200{ }^{\circ} \mathrm{C}$, the doping level decreases further to $<10^{12} \mathrm{~cm}^{-2}$ and the mechanical strain level decreases slightly to between -0.05 and $-0.15 \%$, although the broadening in $\Gamma_{2 \mathrm{D}}$ and $\Gamma_{\mathrm{G}}$ indicates that the variation in the nanometer-scale strain is actually increased (Figure 5d) ${ }^{53}$ It has been known that the presence of hydroxyl species on the $\mathrm{SiO}_{2}$ surface induces the formation of charge trap sites that contribute to the doping level and the buckling behavior of $\mathrm{G} / \mathrm{SiO}_{2}$. During $\mathrm{ALD}$, the concentration of hydroxyl species on the $\mathrm{SiO}_{2}$ surface is strongly reduced because of induced desorption by thermal treatments. ${ }^{51,54}$ In addition, surface saturation by $\mathrm{H}_{2} \mathrm{O}$ during ALD drives the $\mathrm{O}_{2}$ / $\mathrm{H}_{2} \mathrm{O}$ redox reaction on $\mathrm{SiO}_{2}$ toward $\mathrm{H}^{+}$, which results in the depletion of reactive hydroxyl and peroxide species and leads to the further removal of charge trap sites. ${ }^{54,55}$ Thus, the difference in the doping and mechanical strain levels between $\mathrm{CM}$ and SM may actually be attributed to the difference in $T_{\text {dep }}$, where a higher $T_{\text {dep }}$ leads to a higher removal rate of charge trap sites and thus results in lower doping and strain levels. Note that the level of doping and mechanical strain of graphene is strongly influenced by its substrate. Thus, the changes in the doping and strain levels observed here may occur differently if the graphene is supported by substrates other than $\mathrm{SiO}_{2}$. Nevertheless, this strongly suggests that the 12 ALD cycles in $\mathrm{SM}$ at $200{ }^{\circ} \mathrm{C}$ is a sufficient condition not only for obtaining a homogeneous $\mathrm{AlO}_{x}$ film but also for decreasing the doping and mechanical strain levels of $\mathrm{G} / \mathrm{SiO}_{2}$. As mentioned earlier, the ability to homogeneously deposit ultrathin oxide films on graphene is considered critical for device integration because, for instance, it allows a strong current saturation and a significant gain in voltage and transconductance in highfrequency graphene devices. ${ }^{23}$ While we show that a conformal deposition on graphene is possible, its use as a barrier is yet to be investigated and its quality in terms of, for instance, the leakage current, capacitance, or gas permeation remains to be thoroughly quantified. Nevertheless, future work related to ALD on graphitic surfaces should consider extending the residence time if a conformal nucleation is to be achieved.

\section{CONCLUSIONS}

Our results show that $\mathrm{ALD}$ of $\mathrm{AlO}_{x}$ directly on graphene using the standard $\mathrm{H}_{2} \mathrm{O} / \mathrm{TMA}$ precursors results in nucleation behavior that can be either highly selective or completely homogeneous across the entire surface depending on the deposition conditions. When ALD is performed in CM under a 
wide range of deposition temperatures, the deposition is highly preferential to the most active sites, i.e., ridges of the graphene wrinkles and $\mathrm{Cu}$ surface reconstructions, as long as a noncondensing condition is satisfied. For a condensing condition, the nucleation results in a continuous yet porous $\mathrm{AlO}_{x}$ film with complete coverage of the surface. A more homogeneous $\mathrm{AlO}_{x}$ nucleation can be achieved without relying on $\mathrm{H}_{2} \mathrm{O}$ /TMA condensation by performing ALD in PM, which exposes the graphene surface to $\mathrm{H}_{2} \mathrm{O}$ prior to the actual ALD process. At a typical deposition temperature of $200{ }^{\circ} \mathrm{C}$, the use of PM allows for a more homogeneous nucleation behavior because the nucleation density in the troughs increases proportionally with an increase of the pretreatment time. Nevertheless, this is not a necessary condition because the key to obtaining a conformal nucleation lies in the $\mathrm{H}_{2} \mathrm{O}$ /TMA residence time because an extended residence time is needed to account for the slow adsorption kinetics of the relatively inert graphene surface. Here a prolonged residence time is introduced by optimization to the ALD pulse sequence and a soaking period, in the form of $\mathrm{MM}$ and SM, respectively. Regardless of the method used, be it CM, MM, or SM, when ALD is performed at $200{ }^{\circ} \mathrm{C}$, there exists a critical residence time below which the nucleation is selective and above which it is much more, if not completely, homogeneous across the entire graphene surface. By extending the precursor residence time, we are able to overcome the otherwise heterogeneous nucleation such that sub-2-nm thin continuous $\mathrm{AlO}_{x}$ films can be achieved directly on graphene using standard $\mathrm{H}_{2} \mathrm{O}$ /TMA precursors even at a high $T_{\text {dep }}$ of $200^{\circ} \mathrm{C}$. Because these results could be generally extended to ALD of any other oxides, particularly if homogeneous deposition is required, the work presented here should be considered as a model system for rational $2 \mathrm{D} /$ non- $2 \mathrm{D}$ material process integration, which is relevant to the interfacing and device integration of other emerging $2 \mathrm{D}$ materials, including $\mathrm{hBN}$ and transition-metal dichalcogenides, and many other difficult-to-wet materials.

\section{ASSOCIATED CONTENT}

\section{S Supporting Information}

The Supporting Information is available free of charge on the ACS Publications website at DOI: 10.1021/acsami.6b09596.

Details of ALD parameters, the surface coverage calculation method, effect of the purging time, thickness measurement, electronic property measurement, ellipsometry of $\mathrm{AlO}_{x}$ films, nucleation on bare $\mathrm{Cu}$ and $\mathrm{SiO}_{2}$, and effect of prolonged ozone and TMA exposure (PDF)

\section{AUTHOR INFORMATION}

\section{Corresponding Author}

*E-mail:sh315@cam.ac.uk.

\section{Notes}

The authors declare no competing financial interest.

\section{ACKNOWLEDGMENTS}

We acknowledge funding from the EPSRC (Grant EP/ K016636/1, GRAPHTED) and ERC (Grant 279342, InsituNANO). J.A.A.-W. acknowledges a Research Fellowship from Churchill College, Cambridge, U.K.

\section{REFERENCES}

(1) Ferrari, A. C.; Bonaccorso, F.; Fal'ko, V. I.; Novoselov, K. S.; Roche, S.; Bøggild, P.; Borini, S.; Koppens, F. H. L.; Palermo, V.;
Pugno, N. M.; Garrido, J. a.; Sordan, R.; Bianco, A.; Ballerini, L.; Prato, M.; Lidorikis, E. E.; Kivioja, J.; Marinelli, C.; Ryhänen, T.; Morpurgo, A. F.; Coleman, J. N.; Nicolosi, V.; Colombo, L.; Fert, A.; GarciaHernandez, M.; Bachtold, A.; Schneider, G. F. G. F.; Guinea, F.; Dekker, C.; Barbone, M.; Sun, Z. Z.; Galiotis, C.; Grigorenko, A. N.; Konstantatos, G.; Kis, A.; Katsnelson, M. I.; Vandersypen, L. M. K.; Loiseau, A.; Morandi, V.; Neumaier, D.; Treossi, E.; Pellegrini, V.; Polini, M.; Tredicucci, A.; Williams, G. M.; Hee Hong, B.; Ahn, J.-H.; Min Kim, J.; Zirath, H.; van Wees, B. J.; van der Zant, H.; Occhipinti, L.; Di Matteo, A.; Kinloch, I. A.; Seyller, T.; Quesnel, E.; Feng, X. L.; Teo, K. B. K.; Rupesinghe, N. L.; Hakonen, P. J.; Neil, S. R. T.; Tannock, Q.; Löfwander, T.; Kinaret, J. M. Science and Technology Roadmap for Graphene, Related Two-Dimensional Crystals, and Hybrid Systems. Nanoscale 2015, 7 (11), 4598-4810.

(2) Robinson, J. A.; Labella, M.; Trumbull, K. A.; Weng, X.; Cavelero, R; Daniels, T.; Hughes, Z.; Hollander, M.; Fanton, M.; Snyder, D. Epitaxial Graphene Materials Integration: Effects of Dielectric Overlayers on Structural and Electronic Properties. ACS Nano 2010, 4 (5), 2667-2672.

(3) Liao, L.; Bai, J.; Qu, Y.; Lin, Y.-C.; Li, Y.; Huang, Y.; Duan, X. High- $\kappa$ Oxide Nanoribbons as Gate Dielectrics for High Mobility TopGated Graphene Transistors. Proc. Natl. Acad. Sci. U. S. A. 2010, 107 (15), 6711-6715.

(4) Addou, R.; Dahal, A.; Batzill, M. Growth of a Two-Dimensional Dielectric Monolayer on Quasi-Freestanding Graphene. Nat. Nanotechnol. 2012, 8 (1), 41-45.

(5) Sagade, A. A.; Neumaier, D.; Schall, D.; Otto, M.; Pesquera, A.; Centeno, A.; Elorza, A. Z.; Kurz, H. Highly Air Stable Passivation of Graphene Based Field Effect Devices. Nanoscale 2015, 7 (8), 35583564.

(6) Yamaguchi, J.; Hayashi, K.; Sato, S.; Yokoyama, N. Passivating Chemical Vapor Deposited Graphene with Metal Oxides for Transfer and Transistor Fabrication Processes. Appl. Phys. Lett. 2013, 102 (14), 143505.

(7) Martin, M.-B.; Dlubak, B.; Weatherup, R. S.; Yang, H.; Deranlot, C.; Bouzehouane, K.; Petroff, F.; Anane, A.; Hofmann, S.; Robertson, J.; Fert, A.; Seneor, P. Sub-Nanometer Atomic Layer Deposition for Spintronics in Magnetic Tunnel Junctions Based on Graphene SpinFiltering Membranes. ACS Nano 2014, 8 (8), 7890-7895.

(8) Meyer, J.; Kidambi, P. R.; Bayer, B. C.; Weijtens, C.; Kuhn, A.; Centeno, A.; Pesquera, A.; Zurutuza, A.; Robertson, J.; Hofmann, S. Metal Oxide Induced Charge Transfer Doping and Band Alignment of Graphene Electrodes for Efficient Organic Light Emitting Diodes. Sci. Rep. 2014, 4, 5380.

(9) Wang, W. S.; Wang, D. H.; Qu, W. G.; Lu, L. Q.; Xu, A. W. Large Ultrathin Anatase $\mathrm{TiO} 2$ Nanosheets with Exposed $\{001\}$ Facets on Graphene for Enhanced Visible Light Photocatalytic Activity. J. Phys. Chem. C 2012, 116 (37), 19893-19901.

(10) Liang, Y.; Li, Y.; Wang, H.; Zhou, J.; Wang, J.; Regier, T.; Dai, H. Co3O4 Nanocrystals on Graphene as a Synergistic Catalyst for Oxygen Reduction Reaction. Nat. Mater. 2011, 10 (10), 780-786.

(11) Oh, I.-K.; Tanskanen, J.; Jung, H.; Kim, K.; Lee, M. J.; Lee, Z.; Lee, S.-K.; Ahn, J.-H.; Lee, C. W.; Kim, K.; Kim, H.; Lee, H.-B.-R. Nucleation and Growth of the HfO2 Dielectric Layer for GrapheneBased Devices. Chem. Mater. 2015, 27 (17), 5868-5877.

(12) Shin, W. C.; Bong, J. H.; Choi, S. Y.; Cho, B. J. Functionalized Graphene as an Ultrathin Seed Layer for the Atomic Layer Deposition of Conformal High-K Dielectrics on Graphene. ACS Appl. Mater. Interfaces 2013, 5 (22), 11515-11519.

(13) Wang, X.; Tabakman, S. M.; Dai, H. Atomic Layer Deposition of Metal Oxides on Pristine and Functionalized Graphene. J. Am. Chem. Soc. 2008, 130 (26), 8152-8153.

(14) Lee, B.; Park, S.-Y.; Kim, H.-C.; Cho, K.; Vogel, E. M.; Kim, M. J.; Wallace, R. M.; Kim, J. Conformal Al2O3 Dielectric Layer Deposited by Atomic Layer Deposition for Graphene-Based Nanoelectronics. Appl. Phys. Lett. 2008, 92 (20), 203102.

(15) Lee, B.; Mordi, G.; Kim, M. J.; Chabal, Y. J.; Vogel, E. M.; Wallace, R. M.; Cho, K. J.; Colombo, L.; Kim, J. Characteristics of High-K Al2O3 Dielectric Using Ozone-Based Atomic Layer 
Deposition for Dual-Gated Graphene Devices. Appl. Phys. Lett. 2010, 97 (4), 043107.

(16) Zheng, L.; Cheng, X.; Cao, D.; Wang, G.; Wang, Z.; Xu, D.; Xia, C.; Shen, L.; Yu, Y.; Shen, D. Improvement of Al2O3 Films on Graphene Grown by Atomic Layer Deposition with Pre-H2O Treatment. ACS Appl. Mater. Interfaces 2014, 6 (10), 7014-7019.

(17) Dlubak, B.; Kidambi, P. R.; Weatherup, R. S.; Hofmann, S.; Robertson, J. Substrate-Assisted Nucleation of Ultra-Thin Dielectric Layers on Graphene by Atomic Layer Deposition. Appl. Phys. Lett. 2012, 100 (17), 173113.

(18) Young, M. J.; Musgrave, C. B.; George, S. M. Growth and Characterization of $\mathrm{Al} 2 \mathrm{O} 3$ Atomic Layer Deposition Films on $\mathrm{sp}(2)$ Graphitic Carbon Substrates Using NO2/Trimethylaluminum Pretreatment. ACS Appl. Mater. Interfaces 2015, 7 (22), 12030-12037.

(19) Zhang, Y.; Qiu, Z.; Cheng, X.; Xie, H.; Wang, H.; Xie, X.; Yu, Y.; Liu, R. Direct Growth of High-Quality Al2O3 Dielectric on Graphene Layers by Low-Temperature H2O-Based ALD. J. Phys. D: Appl. Phys. 2014, 47 (5), 055106.

(20) Jeong, S.-J.; Kim, H. W.; Heo, J.; Lee, M.-H.; Song, H. J.; Ku, J.; Lee, Y.; Cho, Y.; Jeon, W.; Suh, H.; Hwang, S.; Park, S. PhysisorbedPrecursor-Assisted Atomic Layer Deposition of Reliable Ultrathin Dielectric Films on Inert Graphene Surfaces for Low-Power Electronics. 2D Mater. 2016, 3 (3), 035027.

(21) Reinke, M.; Kuzminykh, Y.; Hoffmann, P. Surface Reaction Kinetics of Titanium Isopropoxide and Water in Atomic Layer Deposition. J. Phys. Chem. C 2016, 120 (8), 4337-4344.

(22) Gordon, R. G.; Hausmann, D.; Kim, E.; Shepard, J. A Kinetic Model for Step Coverage by Atomic Layer Deposition in Narrow Holes or Trenches. Chem. Vap. Deposition 2003, 9 (2), 73-78.

(23) Han, S.-J.; Reddy, D.; Carpenter, G. D.; Franklin, A. D.; Jenkins, K. A. Current Saturation in Submicrometer Graphene Transistors with Thin Gate Dielectric: Experiment, Simulation, and Theory. ACS Nano 2012, 6 (6), 5220-5226.

(24) Aria, A. I.; Kidambi, P. R.; Weatherup, R. S.; Xiao, L.; Williams, J. A.; Hofmann, S. Time Evolution of the Wettability of Supported Graphene under Ambient Air Exposure. J. Phys. Chem. C 2016, 120 (4), 2215-2224.

(25) Cabrero-Vilatela, A.; Weatherup, R. S.; Braeuninger-Weimer, P.; Caneva, S.; Hofmann, S. Towards a General Growth Model for Graphene CVD on Transition Metal Catalysts. Nanoscale 2016, 8 (4), 2149-2158.

(26) Kratzer, M.; Bayer, B. C.; Kidambi, P. R.; Matković, A.; Gajić, R.; Cabrero-Vilatela, A.; Weatherup, R. S.; Hofmann, S.; Teichert, C. Effects of Polymethylmethacrylate-Transfer Residues on the Growth of Organic Semiconductor Molecules on Chemical Vapor Deposited Graphene. Appl. Phys. Lett. 2015, 106 (10), 103101.

(27) Zhang, Y.; Fu, Q.; Cui, Y.; Mu, R.; Jin, L.; Bao, X. Enhanced Reactivity of Graphene Wrinkles and Their Function as Nanosized Gas Inlets for Reactions under Graphene. Phys. Chem. Chem. Phys. 2013, 15 (43), 19042-19048.

(28) Deng, S.; Berry, V. Wrinkled, Rippled and Crumpled Graphene: An Overview of Formation Mechanism, Electronic Properties, and Applications. Mater. Today 2016, 19 (4), 197-212.

(29) Zhu, W.; Low, T.; Perebeinos, V.; Bol, A. A.; Zhu, Y.; Yan, H.; Tersoff, J.; Avouris, P. Structure and Electronic Transport in Graphene Wrinkles. Nano Lett. 2012, 12 (7), 3431-3436.

(30) Zhang, H.; Zhang, Y.; Wang, B.; Chen, Z.; Zhang, Y.; Sui, Y.; Yu, G.; Jin, Z.; Liu, X. Stripe Distributions of Graphene-Coated Cu Foils and Their Effects on the Reduction of Graphene Wrinkles. RSC Adv. 2015, 5 (117), 96587-96592.

(31) Garces, N. Y.; Wheeler, V. D.; Hite, J. K.; Jernigan, G. G.; Tedesco, J. L.; Nepal, N.; Eddy, C. R.; Gaskill, D. K. Epitaxial Graphene Surface Preparation for Atomic Layer Deposition of Al2O3. J. Appl. Phys. 2011, 109 (12), 124304.

(32) Van Lam, D.; Kim, S.-M.; Cho, Y.; Kim, J.-H.; Lee, H.-J.; Yang, J.-M.; Lee, S.-M. Healing Defective CVD-Graphene through Vapor Phase Treatment. Nanoscale 2014, 6 (11), 5639-5644.
(33) Puurunen, R. L. Surface Chemistry of Atomic Layer Deposition: A Case Study for the Trimethylaluminum/Water Process. J. Appl. Phys. 2005, 97 (12), 121301.

(34) Xuan, Y.; Wu, Y. Q.; Shen, T.; Qi, M.; Capano, M. A.; Cooper, J. A.; Ye, P. D. Atomic-Layer-Deposited Nanostructures for GrapheneBased Nanoelectronics. Appl. Phys. Lett. 2008, 92 (1), 013101.

(35) Zheng, L.; Cheng, X.; Yu, Y.; Xie, Y.; Li, X.; Wang, Z. Controlled Direct Growth of Al2O3 -Doped HfO2 Films on Graphene by H2O-Based Atomic Layer Deposition. Phys. Chem. Chem. Phys. 2015, 17 (5), 3179-3185.

(36) Yeh, C.-H.; Lain, Y.-W.; Chiu, Y.-C.; Liao, C.-H.; Moyano, D. R.; Hsu, S. S. H.; Chiu, P.-W. Gigahertz Flexible Graphene Transistors for Microwave Integrated Circuits. ACS Nano 2014, 8 (8), 76637670.

(37) Kim, K.; Lee, H.-B.-R.; Johnson, R. W.; Tanskanen, J. T.; Liu, N.; Kim, M.-G.; Pang, C.; Ahn, C.; Bent, S. F.; Bao, Z. Selective Metal Deposition at Graphene Line Defects by Atomic Layer Deposition. Nat. Commun. 2014, 5, 4781.

(38) Wu, Q.; Wu, Y.; Hao, Y.; Geng, J.; Charlton, M.; Chen, S.; Ren, Y.; Ji, H.; Li, H.; Boukhvalov, D. W.; Piner, R. D.; Bielawski, C. W.; Ruoff, R. S. Selective Surface Functionalization at Regions of High Local Curvature in Graphene. Chem. Commun. (Cambridge, U. K.) 2013, 49 (7), 677-679.

(39) George, S. M. Atomic Layer Deposition: An Overview. Chem. Rev. 2010, 110 (1), 111-131.

(40) Groner, M. D.; Fabreguette, F. H.; Elam, J. W.; George, S. M. Low-Temperature Al2O3 Atomic Layer Deposition. Chem. Mater. 2004, 16 (4), 639-645.

(41) Saleem, M. R.; Ali, R.; Honkanen, S.; Turunen, J. Thermal Properties of Thin Al2O3 Films and Their Barrier Layer Effect on Thermo-Optic Properties of TiO2 Films Grown by Atomic Layer Deposition. Thin Solid Films 2013, 542, 257-262.

(42) Ylivaara, O. M. E.; Liu, X.; Kilpi, L.; Lyytinen, J.; Schneider, D.; Laitinen, M.; Julin, J.; Ali, S.; Sintonen, S.; Berdova, M.; Haimi, E.; Sajavaara, T.; Ronkainen, H.; Lipsanen, H.; Koskinen, J.; Hannula, S.P.; Puurunen, R. L. Aluminum Oxide from Trimethylaluminum and Water by Atomic Layer Deposition: The Temperature Dependence of Residual Stress, Elastic Modulus, Hardness and Adhesion. Thin Solid Films 2014, 552, 124-135.

(43) Cao, Y.-Q.; Cao, Z.-Y.; Li, X.; Wu, D.; Li, A.-D. A Facile Way to Deposit Conformal Al2O3 Thin Film on Pristine Graphene by Atomic Layer Deposition. Appl. Surf. Sci. 2014, 291, 78-82.

(44) Li, Z.; Wang, Y.; Kozbial, A.; Shenoy, G.; Zhou, F.; McGinley, R.; Ireland, P.; Morganstein, B.; Kunkel, A.; Surwade, S. P.; Li, L.; Liu, H. Effect of Airborne Contaminants on the Wettability of Supported Graphene and Graphite. Nat. Mater. 2013, 12 (10), 925-931.

(45) McDonnell, S.; Pirkle, A.; Kim, J.; Colombo, L.; Wallace, R. M. Trimethyl-Aluminum and Ozone Interactions with Graphite in Atomic Layer Deposition of Al2O3. J. Appl. Phys. 2012, 112 (10), 104110.

(46) Aria, A. I.; Gani, A. W.; Gharib, M. Effect of Dry Oxidation on the Energy Gap and Chemical Composition of CVD Graphene on Nickel. Appl. Surf. Sci. 2014, 293, 1-11.

(47) Jandhyala, S.; Mordi, G.; Lee, B.; Lee, G.; Floresca, C.; Cha, P.R.; Ahn, J.; Wallace, R. M.; Chabal, Y. J.; Kim, M. J.; Colombo, L.; Cho, K.; Kim, J. Atomic Layer Deposition of Dielectrics on Graphene Using Reversibly Physisorbed Ozone. ACS Nano 2012, 6 (3), 27222730.

(48) Goldstein, D. N.; McCormick, J. A.; George, S. M. Al2O3 Atomic Layer Deposition with Trimethylaluminum and Ozone Studied by in Situ Transmission FTIR Spectroscopy and Quadrupole Mass Spectrometry. J. Phys. Chem. C 2008, 112 (49), 19530-19539.

(49) Munz, M.; Giusca, C. E.; Myers-Ward, R. L.; Gaskill, D. K.; Kazakova, O. Thickness-Dependent Hydrophobicity of Epitaxial Graphene. ACS Nano 2015, 9 (8), 8401-8411.

(50) Elam, J. W.; Routkevitch, D.; Mardilovich, P. P.; George, S. M. Conformal Coating on Ultrahigh-Aspect-Ratio Nanopores of Anodic Alumina by Atomic Layer Deposition. Chem. Mater. 2003, 15 (18), $3507-3517$. 
(51) Lee, J. E.; Ahn, G.; Shim, J.; Lee, Y. S.; Ryu, S. Optical Separation of Mechanical Strain from Charge Doping in Graphene. Nat. Commun. 2012, 3, 1024.

(52) Boscá, A.; Pedrós, J.; Martínez, J.; Palacios, T.; Calle, F. Automatic Graphene Transfer System for Improved Material Quality and Efficiency. Sci. Rep. 2016, 6, 21676.

(53) Neumann, C.; Reichardt, S.; Venezuela, P.; Drögeler, M.; Banszerus, L.; Schmitz, M.; Watanabe, K.; Taniguchi, T.; Mauri, F.; Beschoten, B.; Rotkin, S. V.; Stampfer, C. Raman Spectroscopy as Probe of Nanometre-Scale Strain Variations in Graphene. Nat. Commun. 2015, 6, 8429.

(54) Zheng, L.; Cheng, X.; Cao, D.; Wang, Z.; Xia, C.; Yu, Y.; Shen, D. Property Transformation of Graphene with Al2O3 Films Deposited Directly by Atomic Layer Deposition. Appl. Phys. Lett. 2014, 104 (2), 023112.

(55) Levesque, P. L.; Sabri, S. S.; Aguirre, C. M.; Guillemette, J.; Siaj, M.; Desjardins, P.; Szkopek, T.; Martel, R. Probing Charge Transfer at Surfaces Using Graphene Transistors. Nano Lett. 2011, 11 (1), 132137. 
2016-10-10

Parameter space of atomic layer deposition of ultra-thin oxides on graphene

Aria, Adrianus Indrat

ACS Applied Materials and Interfaces

Adrianus I. Aria, Kenichi Nakanishi, Long Xiao, et al., Parameter Space of Atomic Layer

Deposition of Ultrathin Oxides on Graphene, ACS Applied Materials \& Interfaces, 2016, Vol. 8, pÿNumber 44, pp. 3056430575

http://pubs.acs.org/doi/abs/10.1021/acsami.6b09596

Downloaded from Cranfield Library Services E-Repository 